\title{
Novel benzimidazole-based conjugated polyelectrolytes: synthesis, solution photophysics and fluorescent sensing of metal ions
}

https://doi.org/10.1515/epoly-2020-0003

Received July 27, 2019; accepted October 08, 2019.

\begin{abstract}
Two benzimidazole-based conjugated polyelectrolytes (+)-PPBIPV and (-)-PPBIPV which have opposite charges on their side chains were synthesized via Heck coupling reaction and characterized by ${ }^{1} \mathrm{H}-\mathrm{NMR}$, UV-vis and PL spectroscopy. These two polyelectrolytes are both consisted of benzimidazole derivatives and phenylenevinylene units. The absorption and emission spectra reveal that the polymers both have solvent-dependency and concentration-dependency, and they exhibit aggregation effect in aqueous solution. In the respect of ion detection, the aqueous solution of (+)-PPBIPV has excellent selectivity and sensitivity for $\mathrm{Fe}^{3+}$. Moreover, $\mathrm{Pd}^{2+}$ can almost completely quench the fluorescence of (+)-PPBIPV in methanol solution, and its quenching constant $K_{\mathrm{SV}}$ is $5.93 \times 10^{4} \mathrm{M}^{-1}$. For (-)-PPBIPV, $\mathrm{Sn}^{2+}$ can double the fluorescence intensity of its aqueous solution, while (-)-PPBIPV has good identification for $\mathrm{Fe}^{3+}$ in methanol with a $K_{\mathrm{SV}}=3.44 \times 10^{5} \mathrm{M}^{-1}$. Hence, two polyelectrolytes have considerable potential to become effective fluorescent sensing materials for some specific metal ions. All of the stoichiometric relationships between metal ions and conjugated polyelectrolytes were calculated using BenesiHildebrand equation.
\end{abstract}

Keywords: conjugated polyelectrolytes; benzimidazole; fluorescence quenching; Stern-Volmer plot; BenesiHildebrand plot

\footnotetext{
* Corresponding author: Kuan Liu, College of Science, Sichuan Agricultural University, Yaan 625014, China, e-mail: cosmicer@live.cn Yuhan Wei, Lei Xu, Shengjiao He and Hanguang Wang, College of Science, Sichuan Agricultural University, Yaan 625014, China Chenglei Li, Qi Wu and Xianyin Zeng, College of Life Science, Sichuan Agricultural University, Yaan 625014, China
}

\section{Introduction}

Conjugated polyelectrolytes (CPEs) which are a kind of conjugated polymers with water soluble ionic groups have received considerable interests in the past decades. Their ionized side-chain groups make CPEs have excellent solubility in water and other polar solvents. CPEs are a versatile class of materials that have been applied in a variety of photoelectric devices including polymer light-emitting diodes (PLEDs) (1), photovoltaic cells (2) and chemical and biological sensors $(3,4)$. In particular, the chemical structure of CPEs offers several advantages in sensor applications, such as the increasing sensitivity of detection and water solubility. Therefore, CPEs have been widely explored as optical probes for various targets, such as DNA (5), proteins (6), small molecules (7) and metal ions $(7,8)$.

The conjugated polyelectrolytes can be classified into cationic and anionic types depending on the different charged groups introduced on the side chain. Specifically, few cationic conjugated polyelectrolytes were reported and almost all of them were not synthesized directly but prepared by quaternization after the polymerization. Since not all the side groups of the polymers are electrically charged during this process, fully charged cationic polyelectrolytes cannot be obtained by indirect method. In recent years, cationic CPEs have potential applications in biological imaging such as folate receptor (FR) over expressed cancer cells (9), selective recognition of mammalian cells (10) and anionic surfactants (11), monitoring the physical changes of lipid membrane (10). On the other hand, anionic CPEs have been widely applied in the biological and chemical analysis area with their excellent water solubility. Direct electron transfer over a longer working distance can be accomplished through the sulfonated conjugate polyelectrolyte, which has a strong signal in DNA detection (12). And a probe system as fluorescence turn-on assay of simple saccharides is based on three anionic conjugated polyelectrolytes and 
three quenched molecules substituted by boric acid (13). However, almost all the anionic CPEs are consisted of phenyl units (14), thiophene derivatives (15) and fluorene monomers (16), and there are few literatures focused on water soluble N-heterocyclic systems. This can be attributed to complexity of the synthesis and purification. Although the fluorescent sensing properties of conjugated polyelectrolytes in the field of biology and chemistry have been extensively studied, there are few reports on the detection of metal ions in both cationic and anionic conjugate polyelectrolytes.

Benzimidazole is a nitrogen-containing heterocyclic compound fused from an imidazole ring and a benzene ring. With chemical modification by using various specific chemical methods, derivatives of benzimidazole can interact with enzymes, receptors and metal ions in the living body (17). Therefore, they have a wide range of applications in medicine (18) and pesticides (19). In recent years, due to the structural characteristics of benzimidazole, its derivatives have also received extensive attention in the field of fluorescent sensors (20). The $\mathrm{sp}^{2}$ hybridized nitrogen atom on benzimidazole has a lone pair of electrons that can coordinate with metal ions, resulting in changes in optical properties to achieve the purpose of detection (21). Thus, there have been a number of reports about small molecule probes containing benzimidazole $(22,23)$. Related studies on benzimidazolecontaining conjugated polymers reported in the past have mainly focused on light-emitting diodes (24) and photovoltaic devices (25). However, few benzimidazolebased conjugated polymers have been utilized for fluorescent sensors, and they are basically oil soluble (26). Among these studies, most of the fluorescence sensing properties were investigated in non-aqueous system, such as tetrahydrofuran (27). Therefore, it is interesting to develop novel CPEs containing benzimidazole which can detect metal ions in the water effectively.

Herein, we have successfully designed and synthesized two novel conjugated polyelectrolytes cationic PPBIPV ((+)-PPBIPV) and anionic PPBPIV ((-)-PPBIPV), which were modified with quaternary ammonium salt and sulfonate in the side-chain, respectively. First, the synthesis and characterization of two monomers 5-bromo-2-(4bromophenyl)-1-ethyl-1H-benzo[d]imidazole (monomer 1) and 5-bromo-2-(4-bromophenyl) -1-(3-sulfonylpropyl) -1Hbenzo[d]imidazole (monomer 2) were accomplished. And then the two compounds were used as the copolymerization monomers to synthesize (+)-PPBIPV and (-)-PPBIPV via Heck coupling reaction with 1,4-Bis(3-(N,N,N-triethylammonium)-1-oxapropyl)-2, 5-divinyl-benzene dibromide ((+)-DVB) and 1,4-divinyl-2, 5-dibutyloxy-benzene (C4-DVB), respectively. Photophysics properties of (+)-PPBIPV and (-)-PPBIPV were studied with absorption and emission spectra by changing the kind of solvent. In the respect of metal sensing, we used fluorescence spectroscopy to investigate the metal ions response of (+)-PPBIPV and (-)-PPBIPV in aqueous solution and methanol solution, respectively. The fluorescence of these solutions is obviously affected with addition of specific metal ions, and these two polyelectrolytes which are oppositely charged exhibit totally different metal sensing properties, demonstrating their potential as metal ion probes. The results of this study can provide useful suggestions for the design and synthesis of novel conjugated polyelectrolytes materials in the area of fluorescence chemical sensor.

\section{Experimental}

\subsection{Measurements}

${ }^{1} \mathrm{H}$ NMR spectra were recorded on a Bruker Avance II-400MHz spectrometer (Bruker, Karlsruhe, Germany) with tetramethylsilane as an internal reference. UV-vis absorption spectra were performed on an AnalytikJena Specord 200Plus UV-vis spectrophotometer (AnalytikJena, Jena, Germany). Photoluminescence (PL) spectra were measured by using a Hitachi F-4600 luminescence spectrophotometer (Hitachi, Tokyo, Japan). All spectra were measured at room temperature.

\subsection{Materials}

All of chemicals were purchased from Aladdin Industrial Corporation (Aladdin, Shanghai, China) and were used directly without further purification. 1,4-divinyl-2,5dibutyloxy-benzene (C4-DVB) and 1,4-Bis (3-(N,N,Ntriethylammonium)-1-oxapropyl)-2,5-divinyl-benzene dibromide ((+)-DVB) were synthesized according to the literature (28). 4-bromo-2-nitroaniline (1) and 4-bromobenzene-1,2-diamine (2) were prepared following the published procedures $(29,30)$.

\subsubsection{Synthesis of monomers}

\section{5-Bromo-2-(4-bromophenyl)-1H-benzo[d]imidazole (3)}

4-bromobenzaldehyde ( $1.1 \mathrm{~g}, 6 \mathrm{mmol}$ ), sodium bisulfite (0.6 g, $6 \mathrm{mmol})$, and absolute ethanol $(25 \mathrm{~mL})$ were stirred 
at room temperature for $4 \mathrm{~h}$. Then 4-bromobenzene-1,2diamine(2) (1.1 g, $6 \mathrm{mmol})$ dissolved in DMF (15 mL) was added. The reaction mixture was subjected to reflux for $2 \mathrm{~h}$. Subsequently, ethanol in the mixture was removed by rotary evaporation. The residue was dissolved in $20 \mathrm{~mL}$ ethyl acetate and washed with water. The organic phase was dried over anhydrous sodium sulfate, and then filtered. The solvent was removed by rotary evaporation and the crude product was purified by column chromatography (silica gel, petroleum ether/ethyl acetate: 4/1) to give a white solid. Yield: $1.30 \mathrm{~g}, 61.5 \%$. ${ }^{1} \mathrm{H}$ NMR $(400 \mathrm{MHz}$, DMSO-d $\left.\mathrm{d}_{6}, \delta\right): 13.22(\mathrm{~s}, 0.5 \mathrm{H}), 13.18(\mathrm{~s}, 0.5 \mathrm{H}) ; 8.11(\mathrm{~d}, J=$ $6.9 \mathrm{~Hz}, 2 \mathrm{H}) ; 7.90-7.68$ (m, 3H); $7.63(\mathrm{~d}, 0.5 \mathrm{H}), 7.51$ (d, 0.5 H); $7.36(\mathrm{~m}, J=9.4 \mathrm{~Hz}, 1 \mathrm{H})$.

5-Bromo-2-(4-bromophenyl)-1-ethyl-1H-benzo[d]imidazole (monomer 1)

Under argon atmosphere, 5-bromo-2-(4-bromophenyl)1H-benzo[d]imidazole(3) $(1.5 \mathrm{~g}, 4 \mathrm{mmol})$ in DMF (15 mL) was stirred at $0^{\circ} \mathrm{C}$ and then sodium hydride $(60 \%)(0.56 \mathrm{~g}$, $14 \mathrm{mmol}$ ) was added. Subsequently, the mixture was stirred at room temperature for $2 \mathrm{~h}$ and then was heated to $40^{\circ} \mathrm{C}$. Ethyl bromide $(0.54 \mathrm{~g}, 5 \mathrm{mmol})$ was injected through a syringe in $15 \mathrm{~min}$. The mixture was stirred at $80^{\circ} \mathrm{C}$ for $12 \mathrm{~h}$ and then water $(15 \mathrm{~mL})$ was added dropwise slowly. The organic phase was separated and the aqueous layer was extracted with dichloromethane. The combined organic layer was washed with water, dried over anhydrous sodium sulfate, filtered and the solvent was removed by rotary evaporation. The crude product was purified by column chromatography (silica gel, petroleum ether/ethyl acetate: 4/1) to give a white solid. Yield: $0.91 \mathrm{~g}, 63.8 \%$. ${ }^{1} \mathrm{H}$ NMR (400 MHz, $\mathrm{CDCl}_{3}$, ) ): 7.97 (s, 0.5H), 7.64 (dd, $J=$ 33.5, $8.3 \mathrm{~Hz}, 5 \mathrm{H}), 7.47-7.40(\mathrm{~m}, 1 \mathrm{H}), 7.31(\mathrm{~d}, J=8.6 \mathrm{~Hz}, 0.5 \mathrm{H})$; 4.26 (m, 2H); 1.47 (m, 3H).

5-Bromo-2-(4-bromophenyl)-1-(3-sulfonylpropyl)-1H-benzo [d]imidazole (monomer 2)

Under argon atmosphere, 5-bromo-2-(4-bromophenyl)1H-benzo[d]imidazole(3) $(0.7 \mathrm{~g}, 2 \mathrm{mmol})$ in DMF $(10 \mathrm{~mL})$ were stirred at $0^{\circ} \mathrm{C}$ and sodium hydride $(60 \%)(0.32 \mathrm{~g}$, $8 \mathrm{mmol}$ ) was added. Subsequently, the mixture was stirred at room temperature for $2 \mathrm{~h}$ and then was heated to $40^{\circ} \mathrm{C}$. 1,3-Propanesultone $(0.49 \mathrm{~g}, 4 \mathrm{mmol})$ dissolved in $5 \mathrm{~mL}$ DMF was added dropwise in $30 \mathrm{~min}$. Subsequently, the reaction solution was stirred at $90^{\circ} \mathrm{C}$ for $12 \mathrm{~h}$ and cooled to room temperature. The mixture was poured into absolute ether $(150 \mathrm{~mL})$ and the precipitate was collected.
The crude product was dried under vacuum at $60^{\circ} \mathrm{C}$ for $12 \mathrm{~h}$ and was purified by recrystallization from aqueous solution of potassium chloride to give a white solid. Finally this solid was dried under vacuum overnight again. Yield: 0.56 g, 56.4\%. ${ }^{1} \mathrm{H}$ NMR (400 MHz, DMSO-d 6 , 8$): 8.04$ (d, $J=$ $1.7 \mathrm{~Hz}, 0.5 \mathrm{H}), 7.89(\mathrm{~d}, J=1.8 \mathrm{~Hz}, 0.5 \mathrm{H}) ; 7.82-7.62(\mathrm{~m}, 5 \mathrm{H}) ; 7.42$ (ddd, $J=22.8,8.6,1.8 \mathrm{~Hz}, 1 \mathrm{H})$; 4.46 (dd, $J=15.0,6.5 \mathrm{~Hz}, 2 \mathrm{H}$ ); $2.39(\mathrm{td}, J=7.1,3.7 \mathrm{~Hz}, 2 \mathrm{H}) ; 2.0-1.93(\mathrm{~m}, 2 \mathrm{H})$.

\subsubsection{Synthesis of polymers}

\section{(+)-PPBIPV}

Under argon atmosphere, monomer $1(0.29 \mathrm{~g}, 0.5 \mathrm{mmol})$, (+)-DVB (0.18 g, $0.5 \mathrm{mmol})$, palladium acetate $(0.011 \mathrm{~g}$, $0.05 \mathrm{mmol})$, tri(o-tolyl)phosphine $(0.061 \mathrm{~g}, 0.2 \mathrm{mmol})$ and diisopropylamine $(2 \mathrm{~mL})$, toluene $(1.5 \mathrm{~mL})$ and DMSO $(2 \mathrm{~mL})$ was stirred in a two-neck flask at $100^{\circ} \mathrm{C}$ for $6 \mathrm{~h}$. The reaction mixture was filtered and the filtrate was poured into the mixed solvent (ethyl ether/acetone/methanol: $8 / 6 / 1)$. The precipitate was filtered and then redissolved in DMSO $(10 \mathrm{~mL})$. The resulting solution was dialyzed against deionized water for 3 days using a $4 \mathrm{kD}$ MWCO cellulose membrane. Finally, the solvent was removed by rotary evaporation and the crude product was further dried under vacuum at $60^{\circ} \mathrm{C}$ for $48 \mathrm{~h}$ to give a yellow solid. Yield: $0.1128 \mathrm{~g}, 27.3 \%$. ${ }^{1} \mathrm{H}$ NMR ( $400 \mathrm{MHz}$, DMSO- $\mathrm{d}_{6}$, 8): 8.16-7.34 (m, 13H), 4.84-4.24 (m, 6H), $3.91(\mathrm{~s}, 4 \mathrm{H}), 3.51$ (s, 12H), 1.65-0.81 (m, 21H).

\section{(-)-PPBIPV}

Under argon atmosphere, the mixture solution of monomer 2 (0.25 g, $0.5 \mathrm{mmol})$, C4-DVB (0.14 g, $0.5 \mathrm{mmol})$, palladiumacetate $(0.011 \mathrm{~g}, \quad 0.05 \mathrm{mmol}), \quad$ tri(o-tolyl) phosphine (0.061 g, $0.2 \mathrm{mmol}$ ) and diisopropylamine $(2.5 \mathrm{~mL})$ and DMF ( $3 \mathrm{~mL}$ ) was stirred at $100^{\circ} \mathrm{C}$ for $6 \mathrm{~h}$. The reaction mixture was poured into methanol $(20 \mathrm{~mL})$ with dimethylglyoxime $(0.158 \mathrm{~g})$ and stirred for $10 \mathrm{~min}$. The mixture solution was filtered and the filtrate was poured into the mixed solvent (ethyl ether/acetone: 1/1). The precipitate was filtered and then redissolved in DMSO $(10 \mathrm{~mL})$. The resulting solution was dialyzed against deionized water for 3 days using a 4kD MWCO cellulose membrane. Finally, the solvent was removed by rotary evaporation and the crude product was further dried under vacuum at $60^{\circ} \mathrm{C}$ for $48 \mathrm{~h}$ to give a yellow-brown solid. Yield: $0.1387 \mathrm{~g}, 43.4 \%$. ${ }^{1} \mathrm{H}$ NMR (400 MHz, DMSO- $\left.\mathrm{d}_{6}, 8\right): 8.13-6.87$ (m, 13H), 4.55 (s, 2H), $4.12(\mathrm{~d}, \mathrm{~J}=37.1 \mathrm{~Hz}, 4 \mathrm{H}), 2.25-0.61$ (m, 18H). 


\section{Results and discussion}

\subsection{Synthesis and characterization of monomers and polymers}

The synthetic schemes for the monomers and the polymers are outlined in Scheme 1. During the formation of the imidazole ring, the position of the bromine substituent on the benzimidazole ring will be at the 4th or 5th position due to the different positions of oxidative dehydrogenation, and therefore compound 3 is a mixture. of course, monomer 1 and monomer 2 derived from the nitrogen alkylation of compound 3 are also mixtures.

The polymerization of the two polymers were both carried out via Heck coupling reaction using $\mathrm{Pd}(\mathrm{OAc})_{2}$ as catalyst and $\mathrm{P}$ (o-tolyl $)_{3}$ as the corresponding ligand (31). Taking into account the presence of water soluble<smiles>CC(=O)O[Sb](=O)(=O)c1ccccc1[N+](=O)[O-]</smiles>

$\mathrm{Br}$<smiles></smiles>
3<smiles>Nc1ccc(Br)cc1[N+](=O)[O-]</smiles>

1<smiles>C[SnH3]</smiles><smiles>[B]C1CCC1</smiles><smiles>Nc1ccc(F)cc1N</smiles><smiles>CCn1c(-c2ccc(Br)cc2)nc2cc(Br)ccc21</smiles>

Monomer 1

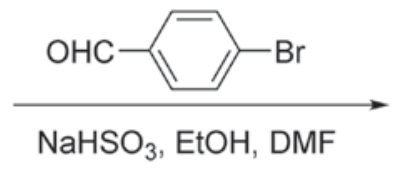

$\mathrm{NaH} / \mathrm{DMF}$<smiles></smiles><smiles>C=Cc1cc(OCC[N+](CC)(CC)CC)c(C=C)cc1OCC[N+](C)(CC)CC[NH+](CC)CCOC</smiles>

$(+)$-DVB

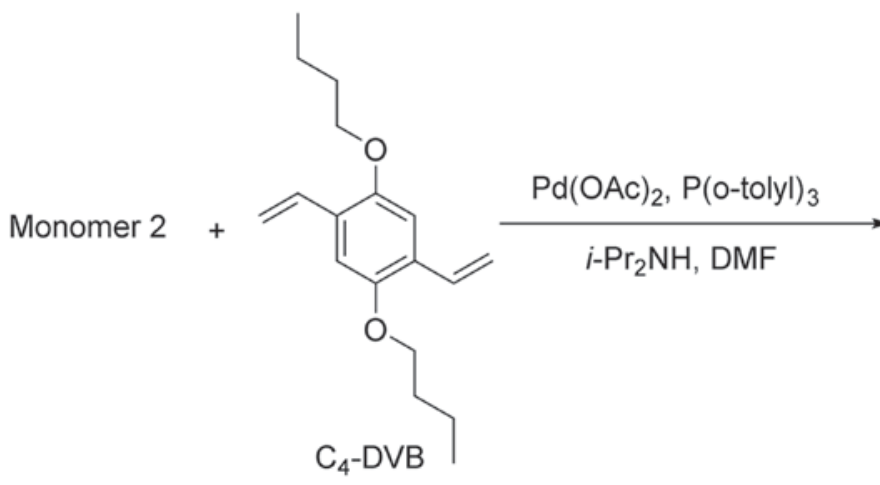<smiles>CCn1c(-c2ccc(/C=C/c3cc(OCC[N+](Br)(CC)CC)c(/C=C/C(C)[In])cc3OCC[N+](CC)(CC)CC)cc2)nc2cc(C)ccc21</smiles>

$(+)-P P B I P V$

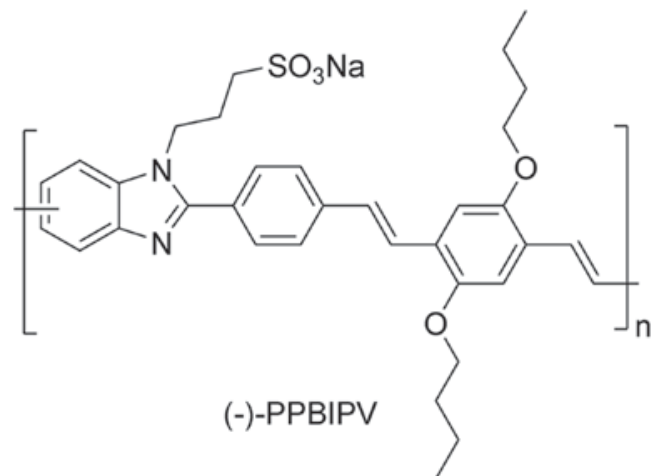

Scheme 1: Synthetic routes of monomers and polymers. 
monomers and oil soluble monomers, we chose DMF that can dissolve most of the substances as solvent. During the procedure of the copolymerization, the conjugated length of (+)-PPBIPV and (-)-PPBIPV which was detected by the UV-vis spectrum was adjusted to be almost identical by controlling the polymerization time.

As shown in Figure 1, it can be seen that the characteristic peaks of polymer (+)-PPBIPV correspond well with the characteristic peaks of each monomer. Specifically, in the ${ }^{1} \mathrm{H}$ NMR spectrum of (+)-PPBIPV, the presence of the peaks at $0.81-1.65 \mathrm{ppm}$ is attributed to the characteristic peak of the methyl group in the alkyl side chain of monomer 1 and (+)-DVB; the peaks at $3.51 \mathrm{ppm}$ and $3.91 \mathrm{ppm}$ are all attributed to the hydrogen of $\mathrm{N}-\mathrm{CH}_{2}$ on the quaternary ammonium group in (+)-DVB; the peaks at 4.24-4.84 $\mathrm{ppm}$ are respectively attributed to $\mathrm{O}-\mathrm{CH}_{2}$ of (+)-DVB unit and $\mathrm{N}-\mathrm{CH}_{2}$ of monomer 1 unit. Since the polymer is not a single pure material but a mixture of different molecular weights, a broad peak usually appears in the NMR spectrum of the polymer. Furthermore, the polymer is a compound with a large delocalized $\pi$ bond, hydrogen atoms in the conjugated structure are often subjected to complex de-shielding effects, so the peaks at 7.34-8.16 ppm are the peaks of aromatic hydrogen atoms in the polymer backbone.

Figure 2 shows the ${ }^{1} \mathrm{H}$ NMR spectra of monomer 2, C4-DVB and (-)-PPBIPV. In the ${ }^{1} \mathrm{H}$ NMR spectrum of (-)-PPBIPV, the presence of the peaks at $0.56-2.10 \mathrm{ppm}$ is attributed to the signal peaks generated by hydrogen atoms not adjacent to oxygen and nitrogen atoms on the alkyl side chains, showing the monomer 2 and C4-DVB units have been introduced into the main chain of (-)-PPBIPV. These results can also be found in the spectrum of (+)-PPBIPV in Figure 1. Moreover, the hydrogen atoms adjacent to oxygen and nitrogen atoms in the alkyl side chain appear at 3.84-4.55 ppm, and the signals in the region of 6.97-8.09 ppm are due to the hydrogen atoms of benzene ring.

It is well-known that CPEs can aggregate in its solution and that aggregated polymers can be easily absorbed on the chromatographic column, so precise molecular weight information of CPEs is difficult to obtain from

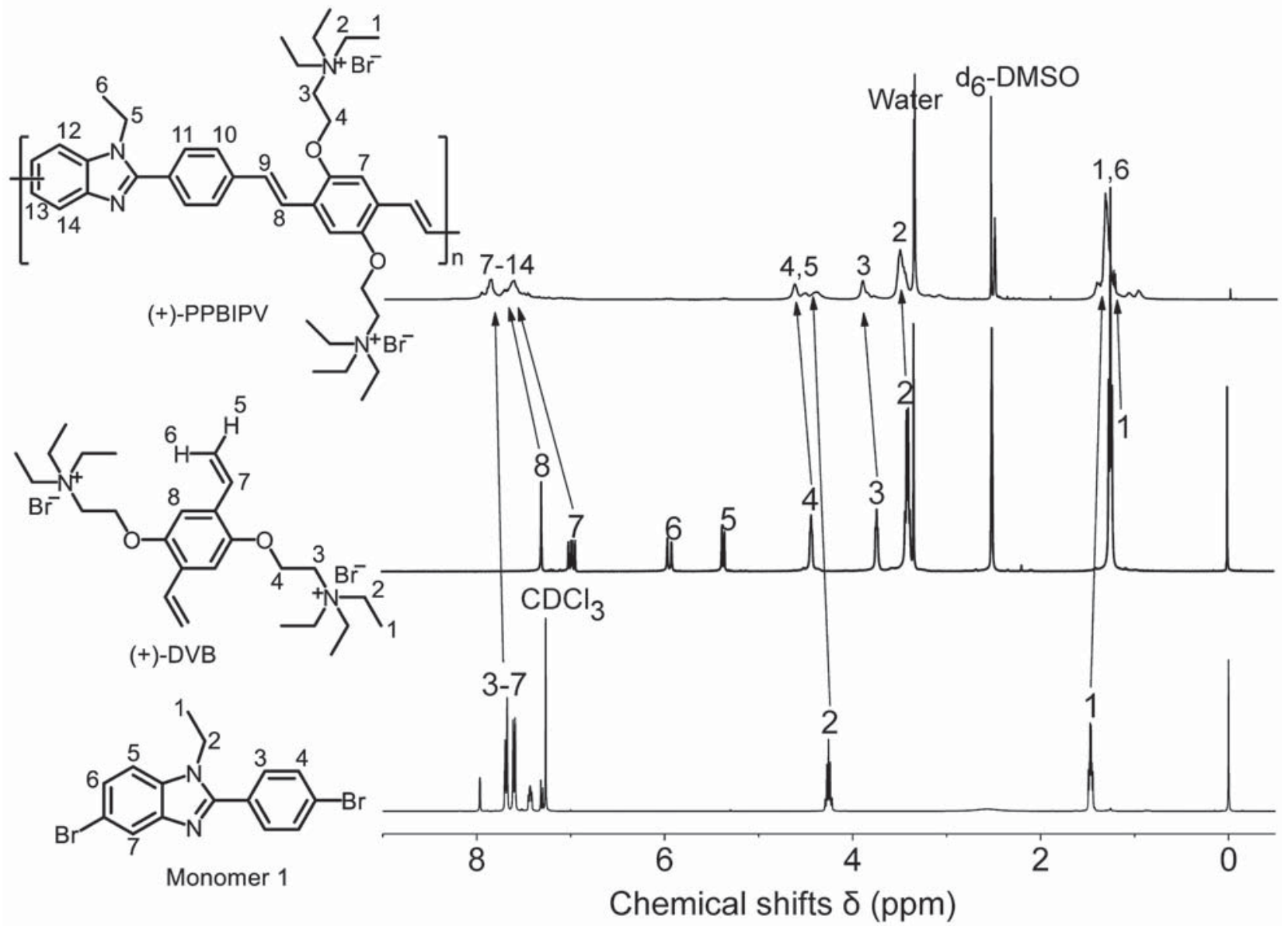

Figure 1: ${ }^{1} \mathrm{H}$ NMR spectra of monomer $1,(+)$-DVB and (+)-PPBIPV. 


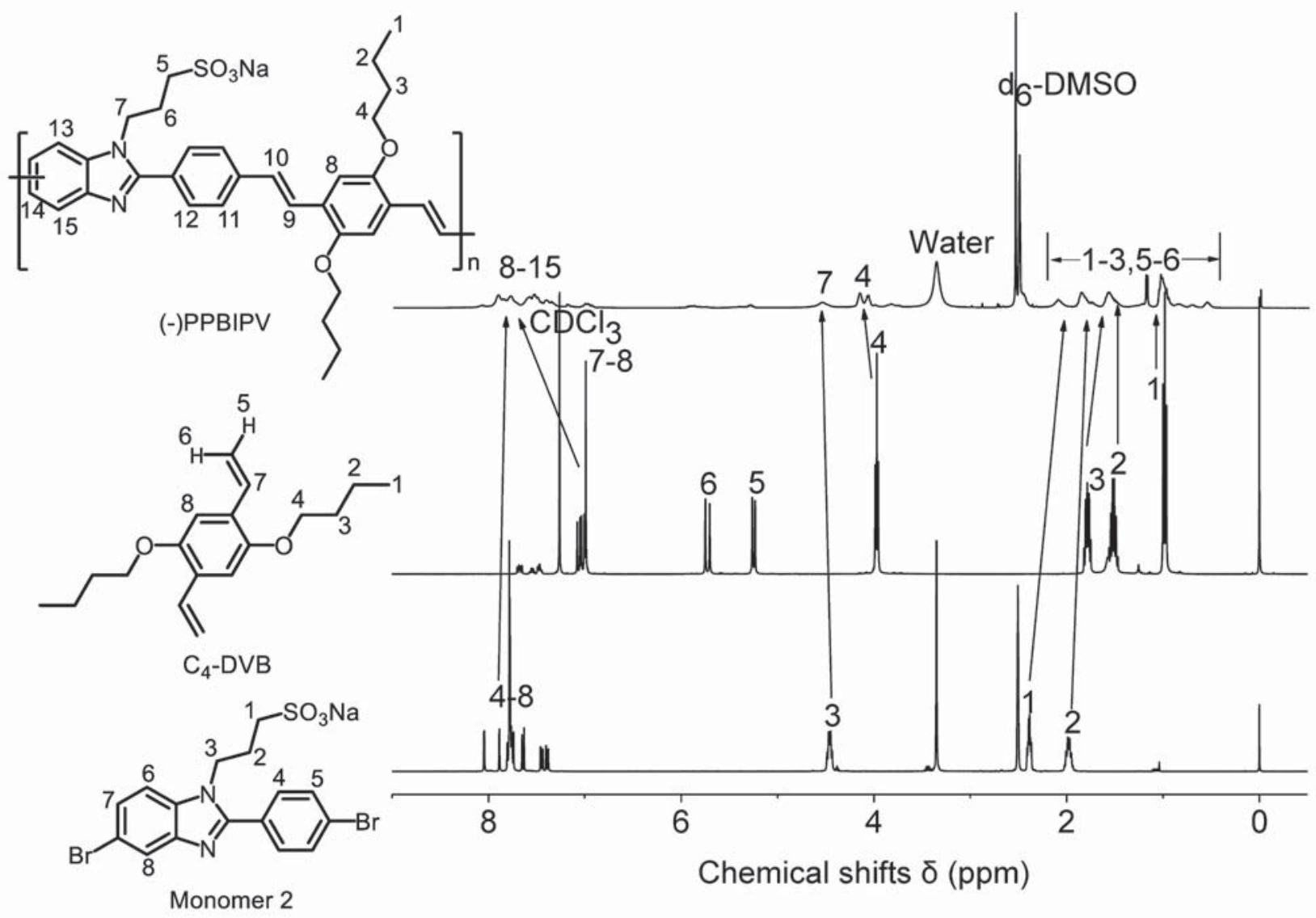

Figure 2: ${ }^{1} \mathrm{H}$ NMR spectra of monomer 2, C4-DVB and (-)-PPBIPV.

gel permeation chromatography (GPC). Another reason is that it is difficult to find a suitable solvent to conform to the measurement requests. Furthermore, owing to the aggregation phenomenon of CPEs, light scattering which is the common technique to measure the molecular weight as same as GPC is not available $(32,33)$. Thus, the solutions of (+)-PPBIPV and (-)-PPBIPV were dialyzed by $4 \mathrm{kD}$ MWCO cellulose membrane, which ensured that the molecular weight of polymers were more than 4000 (at least eight repeating units). Although we can only get a general result in this way, but it is enough to prove that the polymerization of the two CPEs has been completed successfully and satisfied the requirement of photophysics and sensing measurement.

\subsection{Basic photophysical properties of polymers}

The absorption and emission data of monomer 1, monomer 2, (+)-DVB, C4-DVB, (+)-PPBIPV and (-)-PPBIPV are listed in Table 1 . In the water, (+)-PPBIPV shows broad absorption band covered 300-500 $\mathrm{nm}$ visible light region and the absorption maximum at $415 \mathrm{~nm}$. This phenomenon is associated with the increasing conjugate chain of the polymer, which decreases the energy from ground state to excited state. The fluorescence of (+)-PPBIPV is green in the solution, while the fluorescence of (+)-DVB and monomer 1 is purple, and its fluorescence intensity is significantly stronger than two monomers. In comparison with monomer 1, the PL emission maximum of (+)-PPBIPV at $501 \mathrm{~nm}$ showing red shifted $139 \mathrm{~nm}$ is attributed to its increasing conjugation degree. In addition, the maxima of absorption peak and fluorescence emission peak of (+)-PPBIPV are much larger than those of monomer 1 and (+)-DVB, which verifies the success of the polymerization.

As same as (+)-PPBIPV, the UV-vis and PL maxima of (-)-PPBIPV both show large red shifts compared to its monomers. (-)-PPBIPV exhibits the absorption maximum at $408 \mathrm{~nm}$ and emission maximum at $613 \mathrm{~nm}$ in the water. There is almost no overlap between the ultraviolet absorption band and the fluorescence emission band of (-)-PPBIPV, and the Stokes shift reaches $205 \mathrm{~nm}$, which 
can effectively prevent fluorescence self-absorption and exhibit the potential of fluorescence sensor materials.

The absorption and emission maxima of (+)-PPBIPV and (-)-PPBIPV are listed in Table 1, while the photos of conjugated polyelectrolytes in different solvents are shown in Figure 3. As shown in Figure 3a, the maximum absorption peak of (+)-PPBIPV is located in $403 \mathrm{~nm}$ in methanol. However, it exhibits a red shift in water and DMSO, which is located in $415 \mathrm{~nm}$ and $417 \mathrm{~nm}$, respectively. Similarly, when the solvent is changed from methanol to DMSO or water, the emission maximum has been red shifted from $470 \mathrm{~nm}$ (in methanol) to $480 \mathrm{~nm}$ (in DMSO) or $501 \mathrm{~nm}$ (in water). In addition, the PL emission intensity of (+)-PPBIPV is significant in both methanol and DMSO, but weak in aqueous solution. In water, (+)-PPBIPV aggregates strongly by $\pi-\pi$ stacking as same as other conjugated polyelectrolytes (34), which means that the conjugated layers of the polyelectrolytes are stacked mutually. This aggregation causes the conjugated polyelectrolytes to reach a higher degree of conjugation, making it easier for excitons to transfer between the backbones (35). Thus, the fluorescence quenching of (+)-PPBIPV in water may be attributed to energy dissipation caused by excitons transfer.

Figure $3 \mathrm{~b}$ shows that the maximum absorption peaks are located in $417 \mathrm{~nm}$ in DMSO, $408 \mathrm{~nm}$ in water, and $405 \mathrm{~nm}$ in methanol, respectively. In addition, the emission peak of (-)-PPBIPV is located in $500 \mathrm{~nm}$ in methanol, corresponding to the intrinsic emission (36). However, it is worth noting that the fluorescence of (-)-PPBIPV in aqueous solution is very weak, and the emission maximum has been red shifted from $408 \mathrm{~nm}$ to $613 \mathrm{~nm}$, which is consistent with the reported anionic conjugated polyelectrolyte (36). In general, the peak at long wavelength corresponds to aggregation emission in water. The shape of emission peak and the fluorescence solvent dependence are also the same as other sulfonatesubstituted conjugated polyelectrolytes $(36,37)$. Compared to (+)-PPBIPV, the emission maximum of (-)-PPBIPV exhibits a greater red shift in water. This phenomenon

Table 1: Optical properties of (+)-DVB, C4-DVB, monomer 1, monomer 2, (+)-PPBIPV and (-)-PPBIPV.

\begin{tabular}{llccc}
\hline Monomers/Polymers & Solvent & UV-vis max (nm) & PL max (nm) & Stokes Shift (nm)/(cm-1) \\
\hline (+)-DVB & Water & 331 & 387 & $56 / 178571$ \\
C4-DVB & Dichloromethane & 346 & 398 & $52 / 192308$ \\
Monomer 1 & Dichloromethane & 303 & 362 & $59 / 169492$ \\
Monomer 2 & Water & 296 & 368 & $72 / 138889$ \\
(+)-PPBIPV & Water & 415 & 501 & $86 / 116279$ \\
& Methanol & 403 & 470 & $67 / 149254$ \\
(-)-PPBIPV & DMSO & 417 & 480 & $63 / 158730$ \\
& Water & 408 & 613 & $205 / 48780$ \\
& Methanol & 405 & 500 & $95 / 105263$ \\
\hline
\end{tabular}

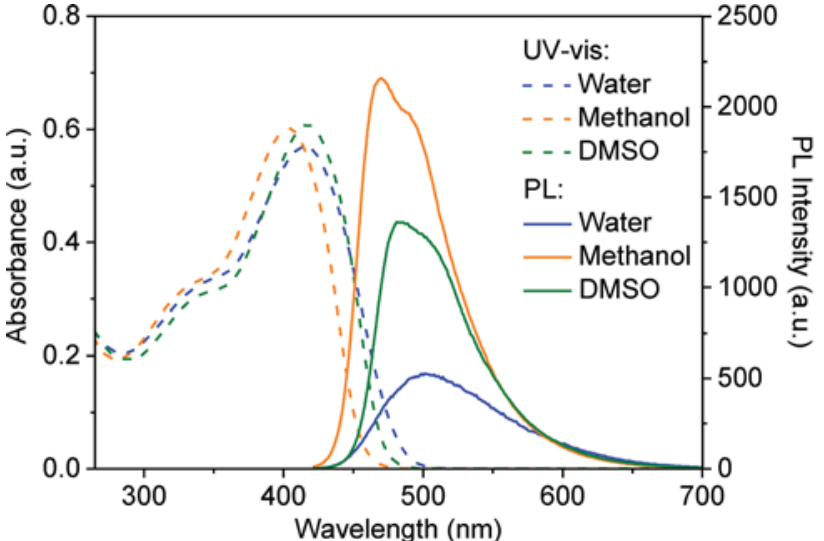

(a)

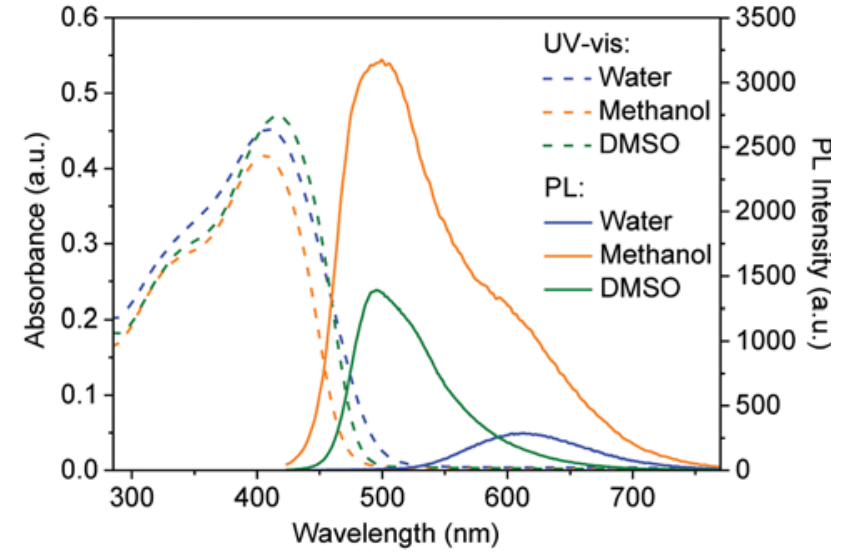

(b)

Figure 3: UV-vis and PL spectra of (+)-PPBIPV in water, methanol and DMSO (a); UV-vis and PL spectra of (-)-PPBIPV in water, methanol and DMSO (b). 
can be attributed to the fact that (-)-PPBIPV has a stronger aggregation effect.

The fluorescence quantum yields $(\Phi)$ of (+)-PPBIPV and (-)-PPBIPV were measured by using quinine sulfate in $0.1 \mathrm{~N}$ sulfuric acid as standard $(\mathrm{n}=1.336, \Phi=55 \%)$ according to the following equation (38):

$$
\Phi_{\mathrm{P}}=\left(\frac{\mathrm{n}_{\mathrm{P}}}{\mathrm{n}_{\mathrm{s}}}\right)^{2} \cdot \frac{\mathrm{F}_{\mathrm{P}}}{\mathrm{F}_{\mathrm{S}}} \cdot \Phi_{\mathrm{S}}
$$

where the subscript $\mathrm{P}$ and $\mathrm{S}$ denote to polymer solution and standard, respectively. $\Phi$ is the fluorescence quantum yield, $\mathrm{F}$ is the intensity of fluorescence, and $\mathrm{n}$ is the refractive index of the solvent.

The $\Phi$ of (+)-PPBIPV and (-)-PPBIPV in methanol are $33 \%$ and $46 \%$, respectively, which are basically consistent to the reference (39). However, the $\Phi$ of benzimidazole-based conjugated polymers is nearly $80 \%$ in THF (24). As reference reported, conjugate polyelectrolytes have lower fluorescence quantum yields than the uncharged oil soluble conjugated polymers of the same main-chain units (39). This phenomenon can be attributed to the fact that (+)-PPBIPV and (-)-PPBIPV aggregate strongly in the solvent, resulting in relatively low fluorescence quantum yields. On the other hand, the benzimidazole units of (+)-PPBIPV and (-)-PPBIPV are fluorescent chromophores, so their fluorescence quantum yields are higher than other PPVtype conjugated polyelectrolytes (40).

\subsection{Metal ions response of polymers}

The fluorescence responses of (+)-PPBIPV and (-)-PPBIPV on various metal ions were investigated. The solutions of metal ion were prepared by $\mathrm{PdCl}_{2}, \mathrm{FeCl}_{3} \cdot 6 \mathrm{H}_{2} \mathrm{O}$, $\mathrm{MgCl}_{2} \cdot 6 \mathrm{H}_{2} \mathrm{O}, \mathrm{SnCl}_{2} \cdot 2 \mathrm{H}_{2} \mathrm{O}, \mathrm{CoCl}_{2} \cdot 6 \mathrm{H}_{2} \mathrm{O}, \mathrm{ZnCl}_{2}, \mathrm{CuSO}_{4} \cdot 5 \mathrm{H}_{2} \mathrm{O}$, $\mathrm{MnSO}_{4} \cdot \mathrm{H}_{2} \mathrm{O}, \mathrm{NiCl}_{2} \cdot 6 \mathrm{H}_{2} \mathrm{O}, \mathrm{Cr}\left(\mathrm{NO}_{3}\right)_{3} \cdot 9 \mathrm{H}_{2} \mathrm{O}, \mathrm{FeSO}_{4} \cdot 7 \mathrm{H}_{2} \mathrm{O}$, $\mathrm{HgCl}_{2}$ and $\mathrm{CdCl}_{2}$, respectively. All of the concentrations of polymers were $2 \times 10^{-5} \mathrm{~mol} / \mathrm{L}$. In metal ion fluorescence sensing experiments (Figure 4 and Figure 7), when the metal ion is added to the polymer solution and the fluorescence intensity of the solution no longer changes, the ion concentration is called the limiting concentration.

\subsection{Sensing properties of (+)-PPBIPV}

Figure 4a shows the PL spectra of aqueous solution of (+)-PPBIPV with $\mathrm{Fe}^{2+}, \mathrm{Zn}^{2+}, \mathrm{Cd}^{2+}, \mathrm{Cr}^{3+}, \mathrm{Hg}^{2+}, \mathrm{Co}^{2+}, \mathrm{Mg}^{2+}$,
$\mathrm{Mn}^{2+}, \mathrm{Ni}^{2+}, \mathrm{Cu}^{2+}, \mathrm{Sn}^{2+}$ and $\mathrm{Fe}^{3+}$. The PL max (nm) and maxima of fluorescence intensity of (+)-PPBIPV with different metal ions are listed in Table 2. It can be found that $\mathrm{Fe}^{3+}, \mathrm{Sn}^{2+}, \mathrm{Cr}^{3+}$ and $\mathrm{Hg}^{2+}$ can reduce the fluorescence of (+)-PPBIPV, but the decrease occurs most notably upon the addition of $\mathrm{Fe}^{3+}$. On the contrary, there is a small increase in fluorescence intensity of (+)-PPBIPV in the presence of $\mathrm{Fe}^{2+}$ and $\mathrm{Cu}^{2+}$. And other metal ions hardly lead to changes in PL spectrum of (+)-PPBIPV. The fluorescence-quenching ratios $\left(\mathrm{I}_{0} / \mathrm{I}_{1}-1\right)$ of aqueous solution of (+)-PPBIPV in the presence of different metal ions are shown in Figure 4c. It should be mentioned that even if the fluorescence quenching ratios of $\mathrm{Sn}^{2+}$ and $\mathrm{Cr}^{3+}$ are 0.34 and 0.25 , respectively, they are still small compared to 1.52 of $\mathrm{Fe}^{3+}$. These results show that (+)-PPBIPV has better fluorescent sensitivity to $\mathrm{Fe}^{3+}$ in aqueous solution.

The PL spectra of methanol solution of (+)-PPBIPV with various metal ions $\left(\mathrm{Fe}^{2+}, \mathrm{Zn}^{2+}, \mathrm{Cd}^{2+}, \mathrm{Cr}^{3+}, \mathrm{Hg}^{2+}\right.$, $\mathrm{Co}^{2+}, \mathrm{Mg}^{2+}, \mathrm{Mn}^{2+}, \mathrm{Ni}^{2+}, \mathrm{Cu}^{2+}, \mathrm{Sn}^{2+}, \mathrm{Fe}^{3+}$ and $\mathrm{Pd}^{2+}$ ) were also investigated (Figure 4b). $\mathrm{Pd}^{2+}$ exhibits the greatest effect on the fluorescence of (+)-PPBIPV methanol solution, which almost completely quenches the fluorescence of the polymer with a quenching rate as high as $99 \%$. Moreover, $\mathrm{Cu}^{2+}, \mathrm{Sn}^{2+}, \mathrm{Fe}^{2+}$ and $\mathrm{Fe}^{3+}$ can partially quench the solution fluorescence and their quenching rates are $72 \%$, 55\%, 44\% and 34\%, respectively. As shown in Figure 4d, the fluorescence quenching ratio of $\mathrm{Pd}^{2+}$ is much larger than other metal ions, indicating that (+)-PPBIPV has high selectivity and excellent sensitivity for $\mathrm{Pd}^{2+}$ in the methanol solution.

Figure 5a gives the fluorescence spectra of (+)-PPBIPV in water with different concentrations of $\mathrm{Fe}^{3+}$. As the concentration of $\mathrm{Fe}^{3+}$ increases, the fluorescence intensity of (+)-PPBIPV is quenched from 2611 to 1121. The fluorescence quenching efficiency of (+)-PPBIPV can be described by the Stern-Volmer equation (41): $\mathrm{I}_{0} / \mathrm{I}_{1}=$ $1+K_{\mathrm{sv}}[\mathrm{Q}]$, where $\mathrm{I}_{0}$ and $\mathrm{I}_{1}$ are the fluorescence intensities of the system in the absence and presence of $\mathrm{Fe}^{3+}$, respectively, $K_{\mathrm{sv}}$ is the Stern-Volmer quenching constant, and $[\mathrm{Q}]$ is the $\mathrm{Fe}^{3+}$ concentration. At the concentrations of $\mathrm{Fe}^{3+}$ between 0 and $162 \mu \mathrm{M}$, a Stern-Volmer plot of the fluorescence intensity of (+)-PPBIPV versus the concentration of $\mathrm{Fe}^{3+}$ is linear with a $K_{\mathrm{SV}}$ value of $7.78 \times 10^{3} \mathrm{M}^{-1}$, as shown in Figure $5 \mathrm{~b}$. The $\mathrm{I}_{0} / \mathrm{I}_{1}$ versus $\left[\mathrm{Fe}^{3+}\right]$ is a straight line, indicating that there is only a single quenching mechanism in this system. Investigating the fluorescence sensor based on benzimidazole, it is found that the quenching mechanism is generally forming a complex between the $\mathrm{sp}^{2}$ nitrogen atom and the metal ions (42). Therefore, the mechanism of fluorescence 


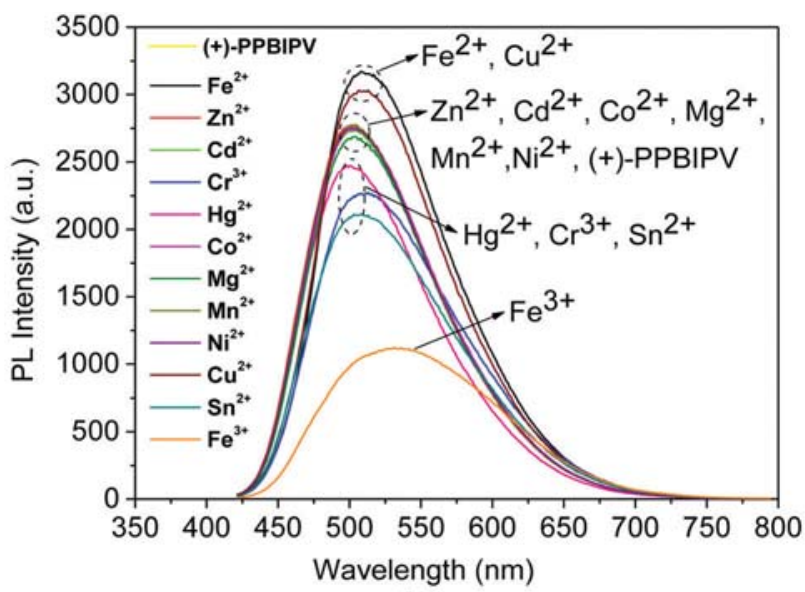

(a)

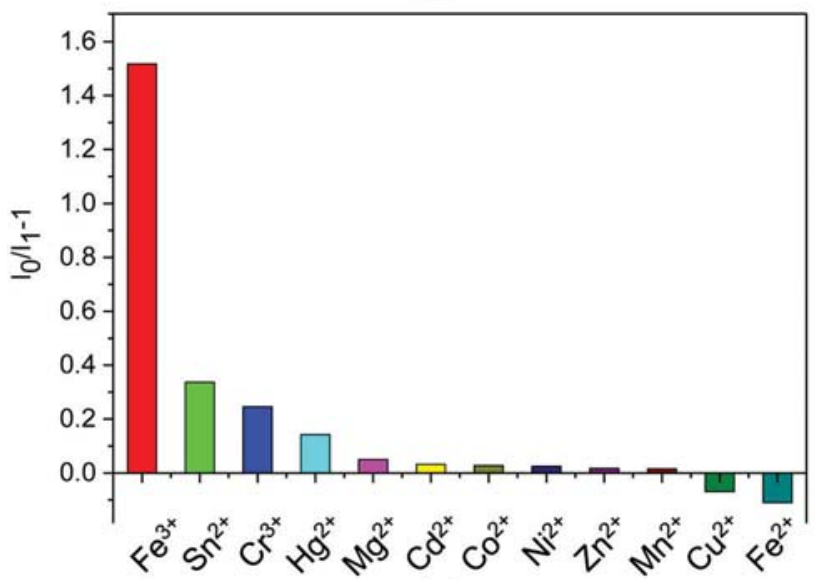

(c)

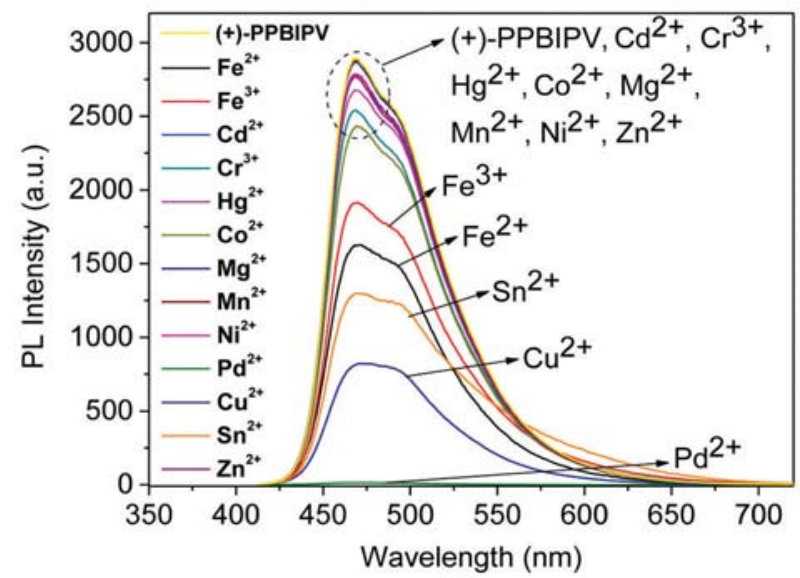

(b)

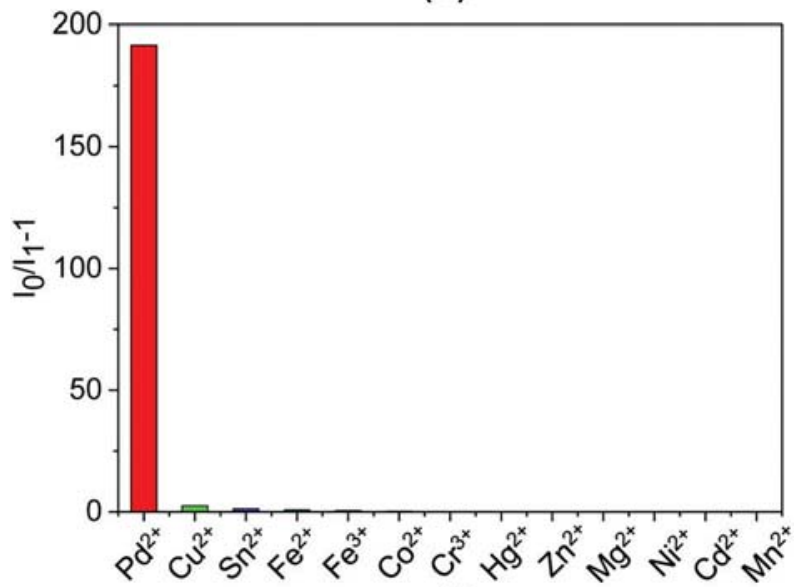

(d)

Figure 4: PL spectra of aqueous solution of (+)-PPBIPV with different metal ions (a); PL spectra of methanol solution of (+)-PPBIPV with different metal ions (b); PL quenching ratios $\left(\mathrm{I}_{0} / \mathrm{I}_{1}-1\right)$ of aqueous solution of $(+)$-PPBIPV with different metal ions (c); PL quenching ratios $\left(I_{0} / I_{1}-1\right)$ of methanol solution of (+)-PPBIPV with different metal ions (d).

Table 2: PL $\max (\mathrm{nm})$ and maxima of fluorescence intensity of (+)-PPBIPV with different metal ions.

\begin{tabular}{|c|c|c|c|c|c|}
\hline \multicolumn{3}{|c|}{ (+)-PPBIPV in water } & \multicolumn{3}{|c|}{ (+)-PPBIPV in methanol } \\
\hline Metal ion & PL max (nm) & Fluorescence intensity (a.u.) & Metal ion & PL max (nm) & Fluorescence intensity (a.u.) \\
\hline blank & 500 & 2822 & blank & 470 & 2889 \\
\hline $\mathrm{Cu}^{2+}$ & 507 & 3030 & $\mathrm{Cu}^{2+}$ & 471 & 821 \\
\hline $\mathrm{Fe}^{3+}$ & 532 & 1121 & $\mathrm{Fe}^{3+}$ & 470 & 1915 \\
\hline $\mathrm{Hg}^{2+}$ & 500 & 2471 & $\mathrm{Hg}^{2+}$ & 468 & 2678 \\
\hline $\mathrm{Cd}^{2+}$ & 504 & 2734 & $\mathrm{Cd}^{2+}$ & 469 & 2870 \\
\hline $\mathrm{Zn}^{2+}$ & 502 & 2774 & $\mathrm{Zn}^{2+}$ & 469 & 2772 \\
\hline $\mathrm{Co}^{2+}$ & 506 & 2746 & $\mathrm{Co}^{2+}$ & 469 & 2434 \\
\hline $\mathrm{Ni}^{2+}$ & 501 & 2753 & $\mathrm{Ni}^{2+}$ & 469 & 2785 \\
\hline $\mathrm{Mg}^{2+}$ & 503 & 2688 & $\mathrm{Mg}^{2+}$ & 468 & 2784 \\
\hline $\mathrm{Cr}^{3+}$ & 508 & 2265 & $\mathrm{Cr}^{3+}$ & 469 & 2542 \\
\hline $\mathrm{Mn}^{2+}$ & 504 & 2779 & $\mathrm{Mn}^{2+}$ & 470 & 2881 \\
\hline $\mathrm{Fe}^{2+}$ & 508 & 3171 & $\mathrm{Fe}^{2+}$ & 472 & 1627 \\
\hline \multirow[t]{2}{*}{$\mathrm{Sn}^{2+}$} & 503 & 2111 & $\mathrm{Sn}^{2+}$ & 471 & 1297 \\
\hline & & & $\mathrm{Pd}^{2+}$ & 473 & 15 \\
\hline
\end{tabular}


quenching of (+)-PPBIPV towards $\mathrm{Fe}^{3+}$ is static quenching in water. The stoichiometric relationship between $\mathrm{Fe}^{3+}$ and (+)-PPBIPV can be determined by the BenesiHildebrand expression based on fluorescence spectra (43): $1 /\left(\mathrm{F}_{0}-\mathrm{F}\right)=1 /\left(\mathrm{K}\left(\mathrm{F}_{0}-\mathrm{F}_{\text {min }}\right)[\mathrm{Q}]^{\mathrm{n}}\right)+1 /\left(\mathrm{F}_{0}-\mathrm{F}_{\text {min }}\right)$, where $\mathrm{F}_{0}$ and $\mathrm{F}$ are the fluorescence intensities in the absence and presence of $\mathrm{Fe}^{3+}$, respectively, $\mathrm{F}_{\text {min }}$ is the minimum fluorescence intensity in the presence of $\mathrm{Fe}^{3+}$, and $\mathrm{K}$ is the association constant. The measured fluorescence intensity $\left[1 /\left(\mathrm{F}_{0}-\mathrm{F}\right)\right]$ varies as a function of $1 /\left[\mathrm{Fe}^{3+}\right](\mathrm{n}=1)$ in a linear $\left(\mathrm{R}^{2}=0.98894\right)$, indicating $1: 1$ stoichiometry between (+)-PPBIPV and $\mathrm{Fe}^{3+}$ (Figure 5c). Furthermore, the $\mathrm{K}$ obtained from the slope and intercept of the line is $1.47 \times 10^{4} \mathrm{M}^{-1}$ for (+)-PPBIPV binding to $\mathrm{Fe}^{3+}$.

Subsequently, we investigated the ability of methanol solution (+)-PPBIPV to detect $\mathrm{Pd}^{2+}$. As Figure 6a shows, the fluorescence intensity of (+)-PPBIPV decreases regularly as the concentration of $\mathrm{Pd}^{2+}$ increases, from 0 to $60 \mu \mathrm{M}$. As shown in Figure 6b, a Stern-Volmer plot of the fluorescence intensity of (+)-PPBIPV versus the concentration of $\mathrm{Pd}^{2+}$ is a upward curve instead of a straight line, which indicates the fluorophore is quenched by both dynamic quenching and static quenching with $\mathrm{Pd}^{2+}$. On the other hand, when the concentration of $\mathrm{Pd}^{2+}$ is between 0 and $15 \mu \mathrm{M}$, a SternVolmer plot of the fluorescence intensity of (+)-PPBIPV versus the concentration of $\mathrm{Pd}^{2+}$ is linear with a $K_{\mathrm{SV}}$ value of $5.93 \times 10^{4} \mathrm{M}^{-1}$, indicating the mechanism of fluorescence quenching of methanol solution (+)-PPBIPV towards $\mathrm{Pd}^{2+}$ is static quenching in the low concentration region. Meanwhile, Benesi-Hildebrand plots of the fluorescence titration combined with (+)-PPBIPV and $\mathrm{Pd}^{2+}$ is yielded linear correlation coefficients of 0.99581 , using the Benesi-Hildebrand equation of linear fitting based on 1:1 binding $(\mathrm{n}=1)$ (Figure $6 \mathrm{c})$. The strong correlation proves that there is 1:1 binding between (+)-PPBIPV and $\mathrm{Pd}^{2+}$, and the $\mathrm{K}$ is calculated as $1.02 \times 10^{4} \mathrm{M}^{-1}$.

All of the measurement methods of (-)-PPBIPV are the same as (+)-PPBIPV. The PL max (nm) and maxima of

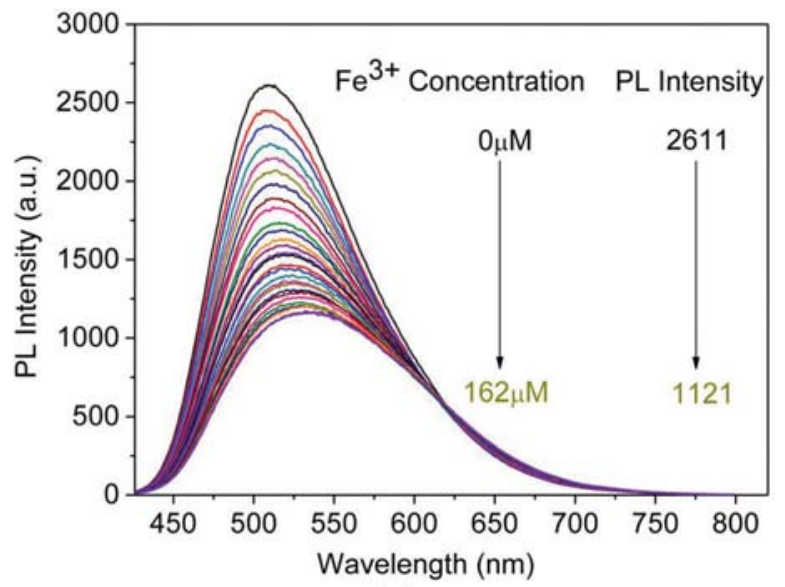

(a)

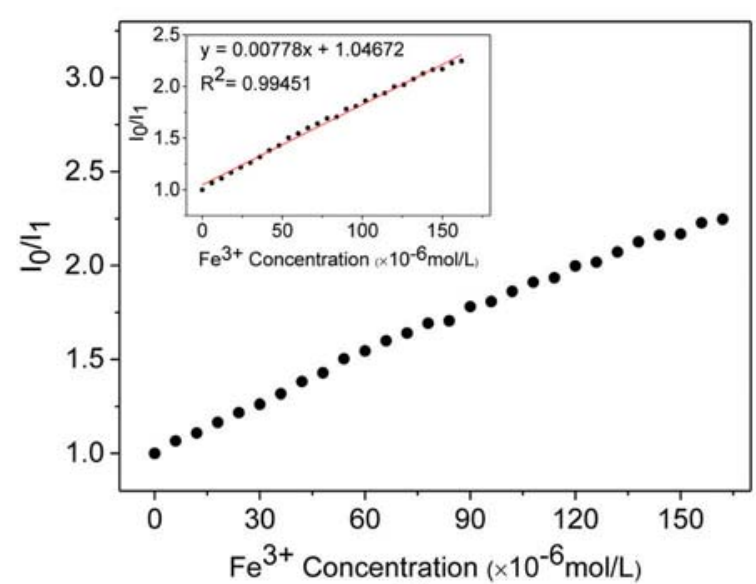

(b)

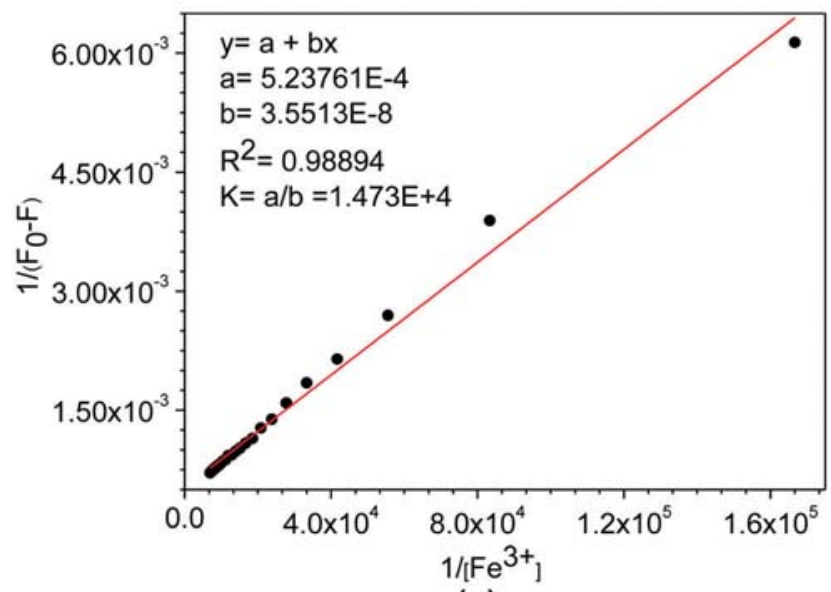

(c)

Figure 5: PL spectra of aqueous solution of (+)-PPBIPV with different concentrations of $\mathrm{Fe}^{3+}(\mathrm{a})$; PL titration curves of aqueous solution of (+)-PPBIPV with $\mathrm{Fe}^{3+}(\mathrm{b})$; The Benesi-Hildebrand plot of aqueous solution of (+)-PPBIPV with Fe ${ }^{3+}(\mathrm{c})$. 


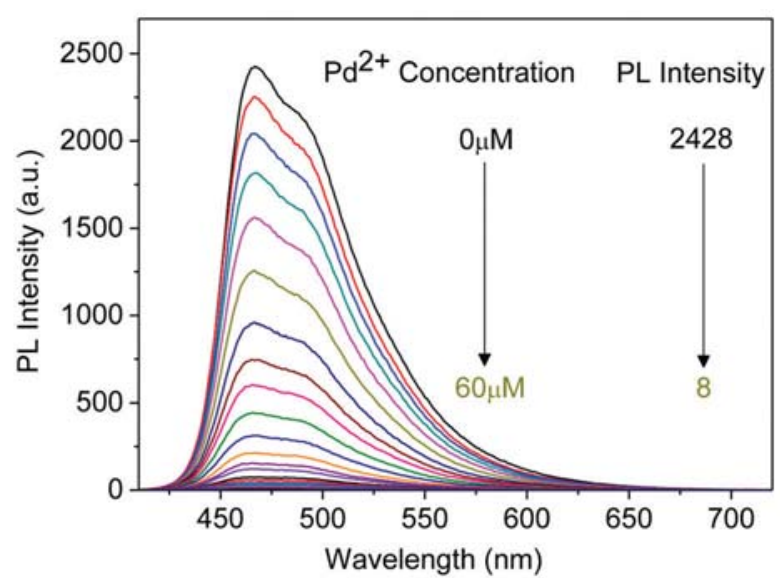

(a)

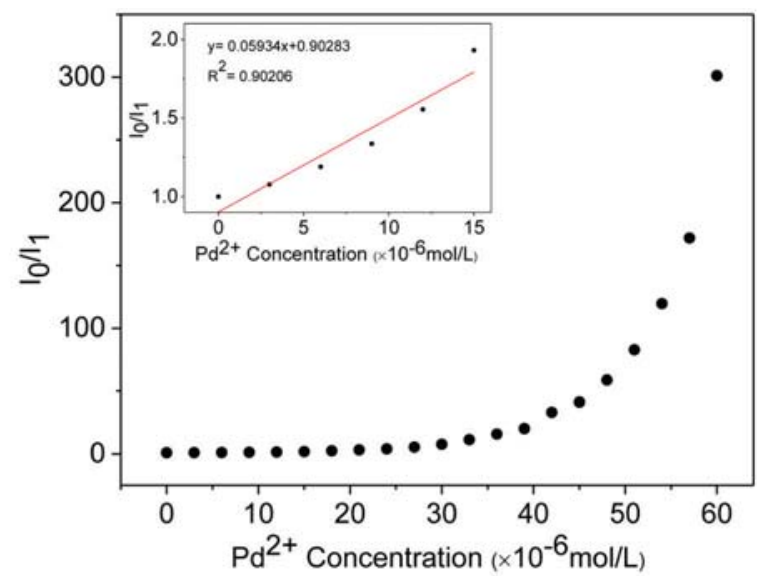

(b)

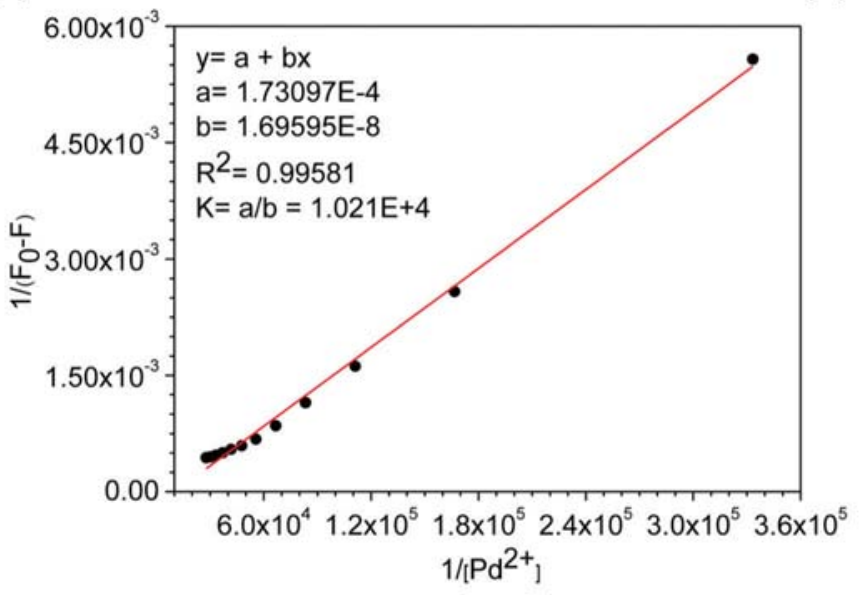

(c)

Figure 6: PL spectra of methanol solution of (+)-PPBIPV with different concentrations of $\mathrm{Pd}^{2+}(\mathrm{a})$; PL titration curves of methanol solution of (+)-PPBIPV with $\mathrm{Pd}^{2+}(\mathrm{b})$; The Benesi-Hildebrand plot of methanol solution of (+)-PPBIPV with $\mathrm{Pd}^{2+}(\mathrm{c})$.

Table 3: PL $\max (\mathrm{nm})$ and maxima of fluorescence intensity of (-)-PPBIPV with different metal ions.

\begin{tabular}{|c|c|c|c|c|c|}
\hline \multicolumn{3}{|c|}{ (-)-PPBIPV in water } & \multicolumn{3}{|c|}{ (-)-PPBIPV in methanol } \\
\hline Metal ion & PL max (nm) & Fluorescence intensity (a.u.) & Metal ion & PL $\max (n m)$ & Fluorescence intensity (a.u.) \\
\hline blank & 613 & 3126 & blank & 500 & 8576 \\
\hline $\mathrm{Cu}^{2+}$ & 612 & 1575 & $\mathrm{Cu}^{2+}$ & 505 & 1529 \\
\hline $\mathrm{Fe}^{3+}$ & 613 & 2894 & $\mathrm{Fe}^{3+}$ & 531 & 210 \\
\hline $\mathrm{Hg}^{2+}$ & 610 & 2898 & $\mathrm{Hg}^{2+}$ & 508 & 1961 \\
\hline $\mathrm{Cd}^{2+}$ & 611 & 2911 & $\mathrm{Cd}^{2+}$ & 500 & 7167 \\
\hline $\mathrm{Zn}^{2+}$ & 609 & 2950 & $\mathrm{Zn}^{2+}$ & 504 & 2726 \\
\hline $\mathrm{Co}^{2+}$ & 615 & 3050 & $\mathrm{Co}^{2+}$ & 502 & 4707 \\
\hline $\mathrm{Ni}^{2+}$ & 613 & 3068 & $\mathrm{Ni}^{2+}$ & 501 & 6198 \\
\hline $\mathrm{Mg}^{2+}$ & 613 & 3139 & $\mathrm{Mg}^{2+}$ & 502 & 7101 \\
\hline $\mathrm{Cr}^{3+}$ & 614 & 3213 & $\mathrm{Cr}^{3+}$ & 603 & 358 \\
\hline $\mathrm{Mn}^{2+}$ & 610 & 3277 & $\mathrm{Mn}^{2+}$ & 502 & 6635 \\
\hline $\mathrm{Fe}^{2+}$ & 611 & 3911 & $\mathrm{Fe}^{2+}$ & 509 & 2819 \\
\hline \multirow[t]{2}{*}{$\mathrm{Sn}^{2+}$} & 613 & 5430 & $\mathrm{Sn}^{2+}$ & 614 & 564 \\
\hline & & & $\mathrm{Pd}^{2+}$ & 510 & 369 \\
\hline
\end{tabular}




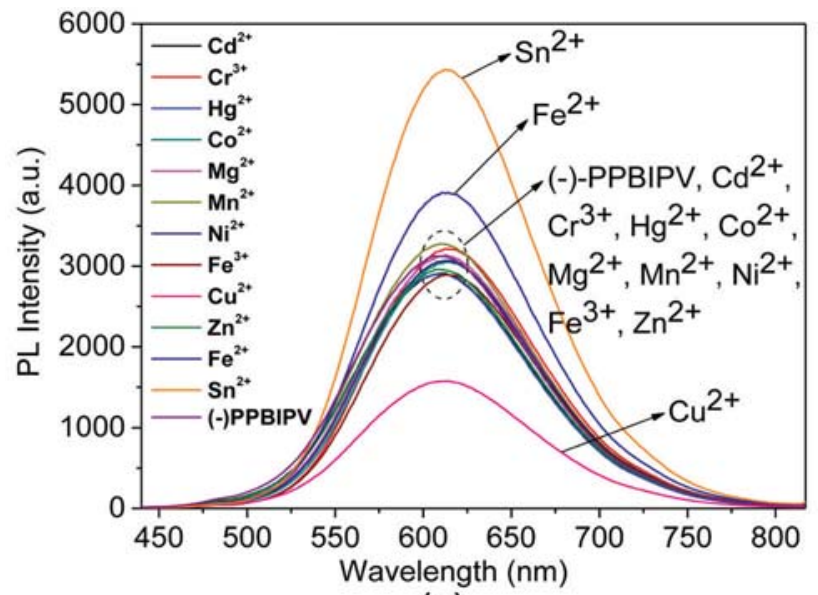

(a)

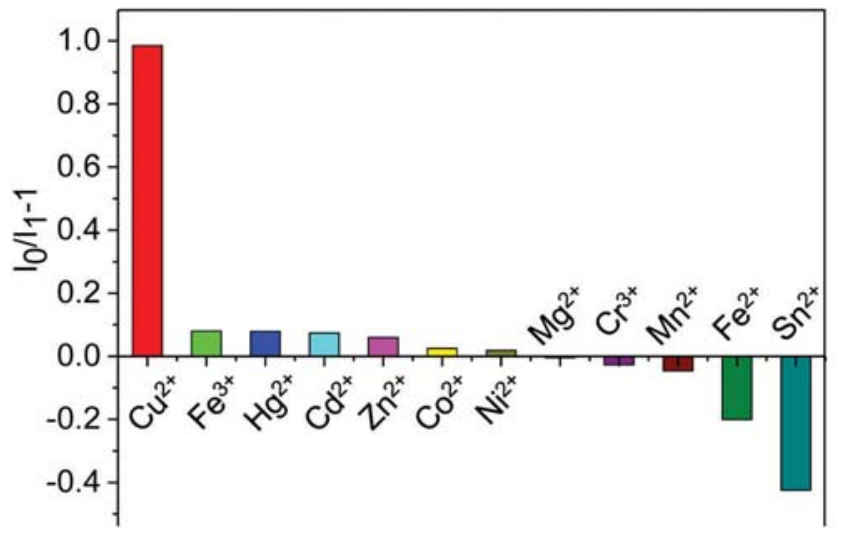

(c)

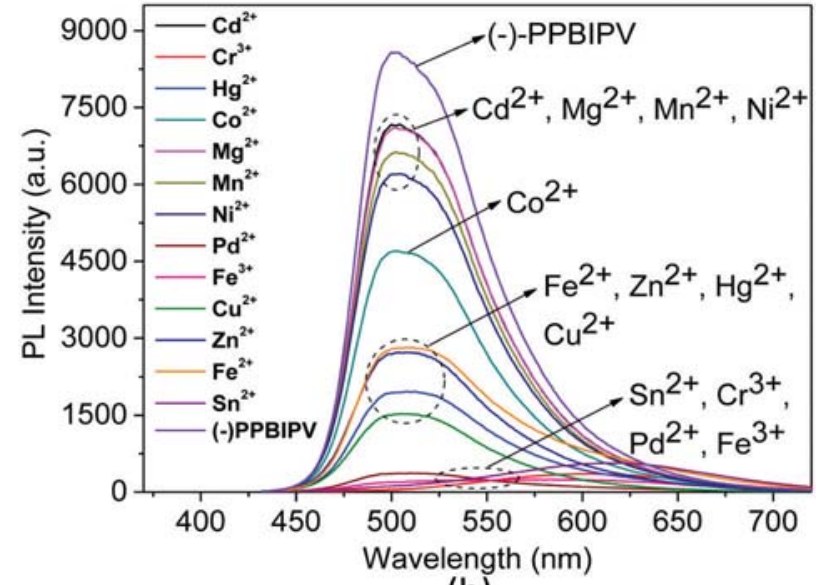

(b)

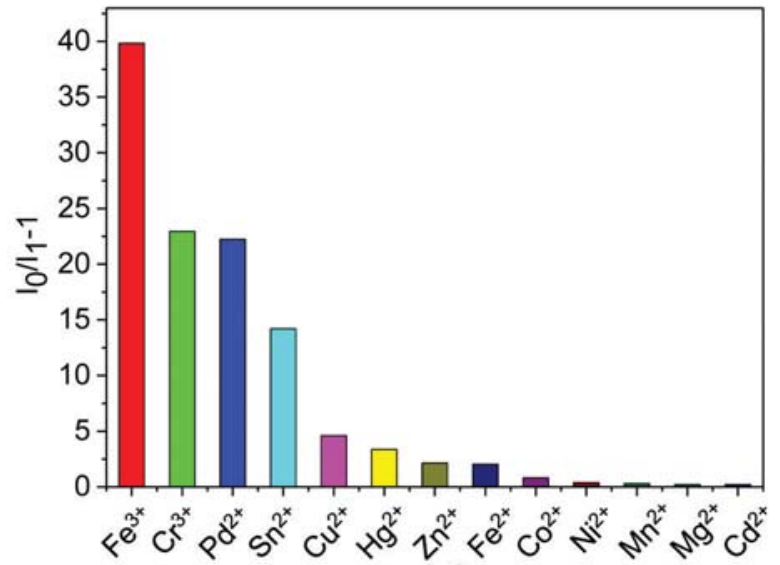

(d)

Figure 7: PL spectra of aqueous solution of (-)-PPBIPV with different metal ions (a); PL spectra of methanol solution of (-)-PPBIPV with different metal ions (b); PL quenching ratios $\left(I_{0} / I_{1}-1\right)$ of aqueous solution of (-)-PPBIPV with different metal ions (c); PL quenching ratios $\left(I_{0} / I_{1}-1\right)$ of methanol solution of (-)-PPBIPV with different metal ions $(d)$.

fluorescence intensity of (-)-PPBIPV with different metal ions are listed in Table 3. As shown in Figures 7a and 7c, $\mathrm{Cu}^{2+}$ can quench the fluorescence of aqueous solution of (-)-PPBIPV by nearly 50\%. $\mathrm{Zn}^{2+}, \mathrm{Cd}^{2+}, \mathrm{Cr}^{3+}, \mathrm{Hg}^{2+}$, $\mathrm{Co}^{2+}$, $\mathrm{Mg}^{2+}, \mathrm{Mn}^{2+}, \mathrm{Ni}^{2+}$ and $\mathrm{Fe}^{3+}$ exhibit little or no effect on the fluorescence intensity of the polymer. Both $\mathrm{Fe}^{2+}$ and $\mathrm{Sn}^{2+}$ can increase the fluorescence, but $\mathrm{Sn}^{2+}$ is more obviously, which doubles the fluorescence intensity of the polymer approximately.

Figure 7b shows the PL spectra of methanol solution of (-)-PPBIPV with different metal ions. Metal ions response of methanol solution of (-)-PPBIPV is more complicated than aqueous solution of (-)-PPBIPV. According to Figure $7 \mathrm{~d}$, the methanol solution of (-)-PPBIPV has certain selectivity for $\mathrm{Fe}^{3+}, \mathrm{Pd}^{2+}, \mathrm{Cr}^{3+}$ and $\mathrm{Sn}^{2+}$, especially $\mathrm{Fe}^{3+}$.

As Figure 8a shows, adding $60 \mu \mathrm{M} \mathrm{Sn}^{2+}$ results in $100 \%$ fluorescence enhancement of (-)-PPBIPV.
Moreover, the Stern-Volmer plot of the fluorescence intensity of (-)-PPBIPV versus the concentration of $\mathrm{Sn}^{2+}$ is a downward curve, which can also be fitted as the equation approximatively, $\mathrm{y}=-0.01325 \mathrm{x}+0.93436$ (Figure 8b). In this system, the addition of $\mathrm{Sn}^{2+}$ increases the fluorescence intensity of (-)-PPBIPV, so the BenesiHildebrand equation takes this form (44): $1 /\left(\mathrm{F}-\mathrm{F}_{0}\right)=$ $1 /\left(\mathrm{K}\left(\mathrm{F}_{\max }-\mathrm{F}_{0}\right)[\mathrm{Q}]^{\mathrm{n}}\right)+1 /\left(\mathrm{F}_{\max }-\mathrm{F}_{0}\right)$, where $\mathrm{F}_{0}$ and $\mathrm{F}$ are the fluorescence intensities in the absence and presence of $\mathrm{Sn}^{2+}$, respectively, $\mathrm{F}_{\max }$ is the maximum fluorescence intensity in the presence of $\mathrm{Sn}^{2+}$, and $\mathrm{K}$ is the association constant. The Benesi-Hildebrand equation fitting curves of the $1 /\left(\mathrm{F}-\mathrm{F}_{0}\right)$ to $1 /\left[\mathrm{Sn}^{2+}\right]$ are shown in Figure $8 \mathrm{c}$, yielded linear correlation coefficients of 0.99655 . The result indicates 1:1 stoichiometry between (-)-PPBIPV and $\mathrm{Sn}^{2+}$, with a $\mathrm{K}$ value of $1.81 \times 10^{4} \mathrm{M}^{-1}$.

Figure 9a shows the fluorescence spectra of the (-)-PPBIPV in methanol solution with the increasing 
concentration of $\mathrm{Fe}^{3+}$. Add $30 \mu \mathrm{M} \mathrm{Fe}$, causing the fluorescence of (-)-PPBIPV to be quenched $97.5 \%$. As shown in Figure 9b, a Stern-Volmer plot of the fluorescence intensity of (-)-PPBIPV versus the concentration of $\mathrm{Fe}^{3+}$ is a non-liner, which is similar to the Stern-Volmer plot of the methanol solution of (+)-PPBIPV with $\mathrm{Pd}^{2+}$. In the low concentration region, the mechanism of fluorescence quenching of methanol solution (-)-PPBIPV towards $\mathrm{Fe}^{3+}$ is static quenching with a $K_{\text {sv }}$ value of $3.44 \times 10^{5} \mathrm{M}^{-1}$. From Figure 9c, the stoichiometric ratio of (-)-PPBIPV to $\mathrm{Fe}^{3+}$ in methanol solution is $1: 1$, and the association constant $\mathrm{K}$ is $5.39 \times 10^{4} \mathrm{M}^{-1}$, which is much larger than the association constant of (+)-PPBIPV and $\mathrm{Fe}^{3+}$ in aqueous solution $\left(\mathrm{K}=1.47 \times 10^{4} \mathrm{M}^{-1}\right)$. Except for the difference in solvent, the reason may be that the side chain of (-)-PPBIPV is a negatively charged sulfonic acid group, which has an electrostatic attraction with metal ions. This force causes a large amount of metal ions to aggregate around the polymer, so metal ions and polymer receptor units can be better combined.

\section{Conclusions}

In summary, two novel benzimidazole-based conjugated polyelectrolytes (+)-PPBIPV and (-)-PPBIPV have been designed, synthesized and characterized successfully. In metal sensing aspects, it is demonstrated that $\mathrm{Fe}^{3+}$ can remarkably reduce the fluorescence of (+)-PPBIPV in aqueous solution. When the concentration of $\mathrm{Fe}^{3+}$ is in the range of 6-66 $\mu \mathrm{M}, \mathrm{Fe}^{3+}$ can be detected by (+)-PPBIPV quantitatively. Furthermore, $\mathrm{Pd}^{2+}$ can quench almost all the fluorescence intensity of the polymer in methanol solution, of which $K_{\mathrm{sv}}$ is $5.93 \times 10^{4}$ $\mathrm{M}^{-1}$, and the results show that there are both static quenching and dynamic quenching in this system. In the low concentration region, there is a single

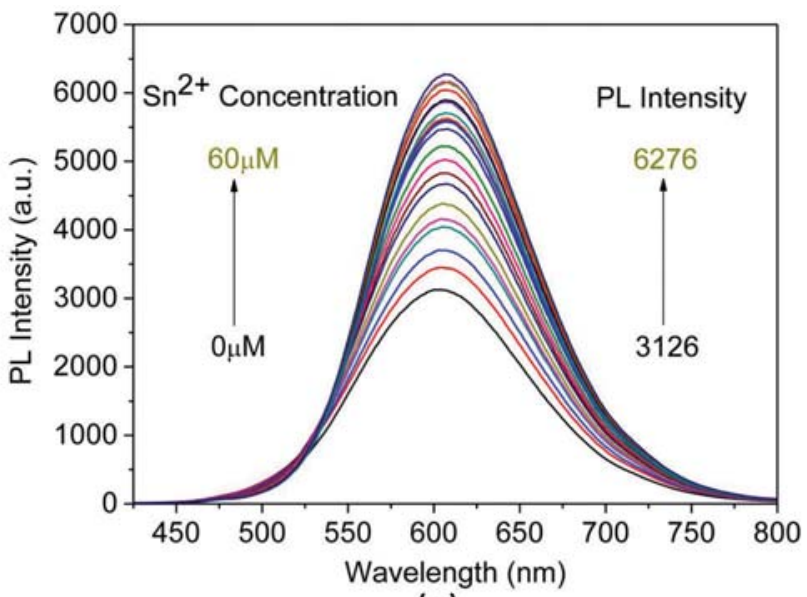

(a)

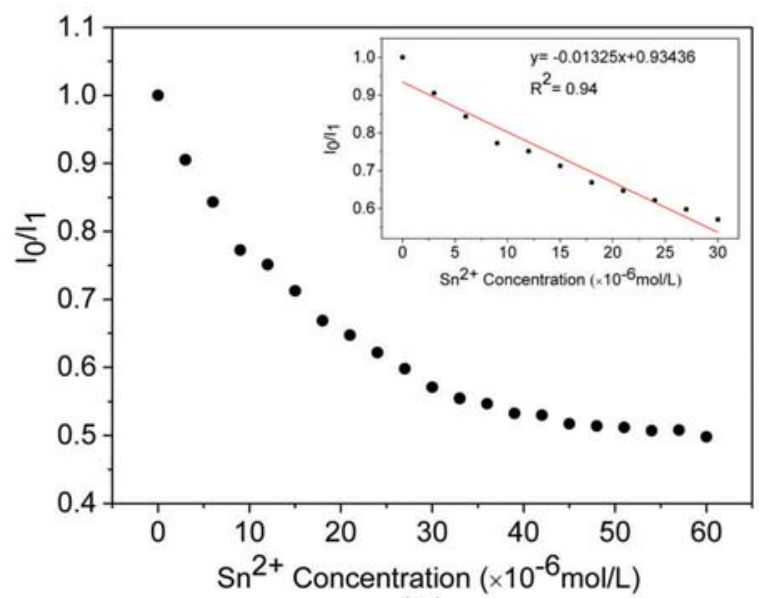

(b)

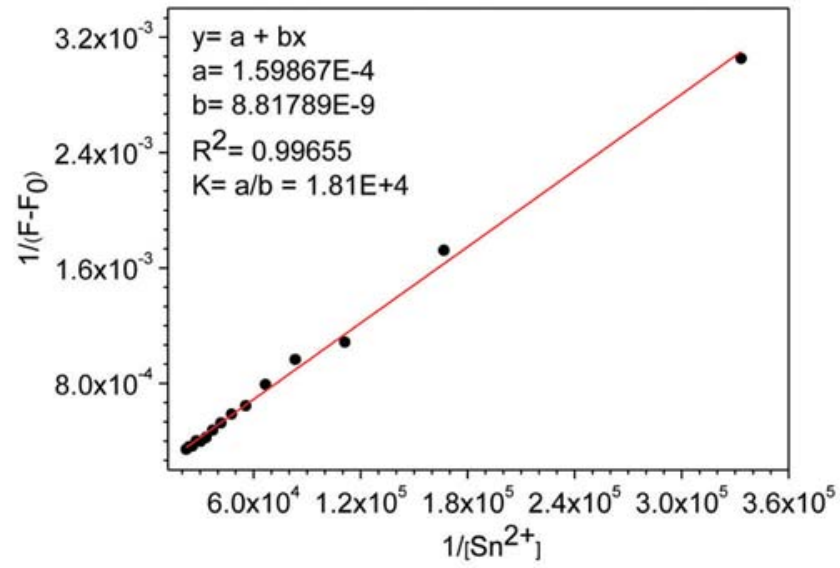

(c)

Figure 8: PL spectra of aqueous solution of (-)-PPBIPV with different concentration of $\mathrm{Sn}^{2+}(\mathrm{a})$; PL titration curves of aqueous solution of (-)-PPBIPV with $\mathrm{Sn}^{2+}(\mathrm{b})$; The Benesi-Hildebrand plot of aqueous solution of (-)-PPBIPV with $\mathrm{Sn}^{2+}(\mathrm{c})$. 


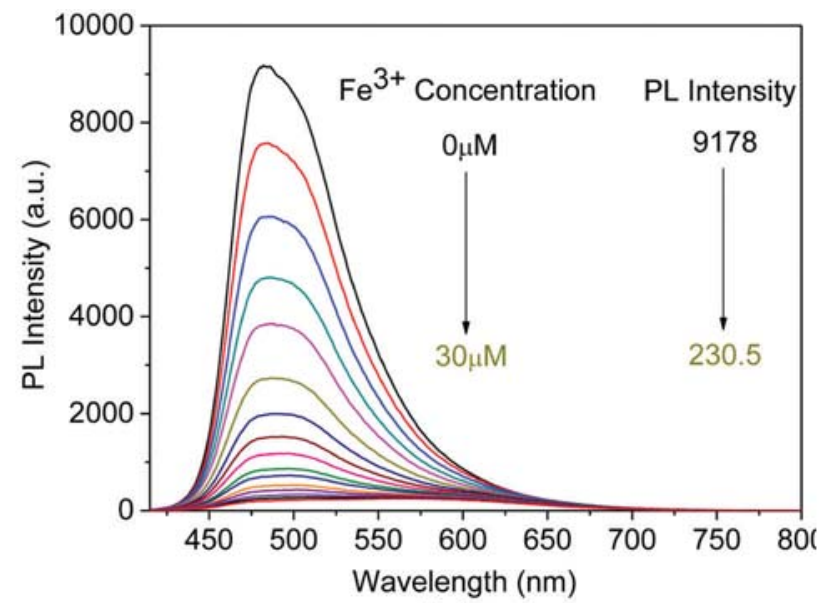

(a)

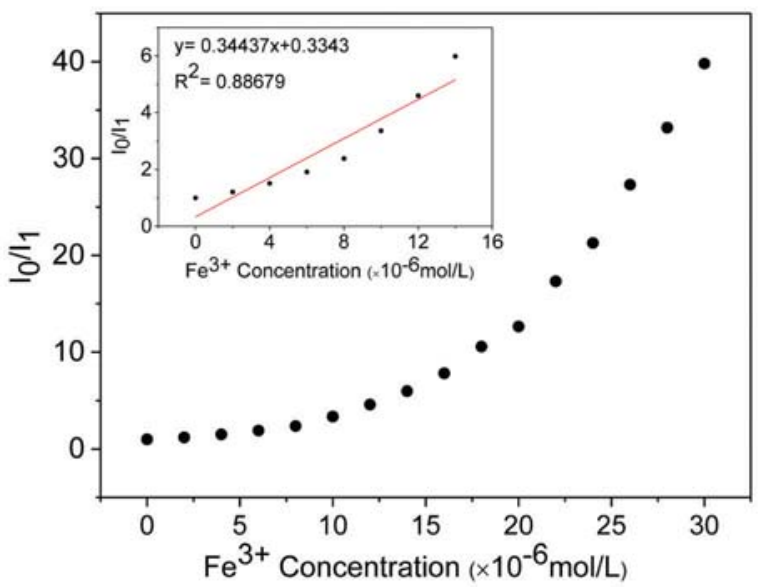

(b)

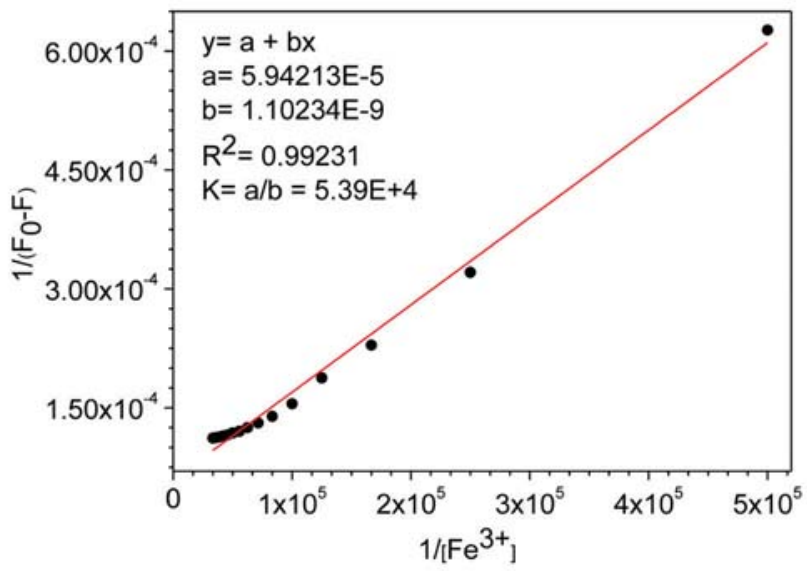

(c)

Figure 9: $\quad P L$ spectra of methanol solution of (-)-PPBIPV with different concentration of $\mathrm{Fe}^{3+}(\mathrm{a})$; PL titration curves of methanol solution of $(-)-P P B I P V$ with $\mathrm{Fe}^{3+}(\mathrm{b})$; The Benesi-Hildebrand plot of methanol solution of (-)-PPBIPV with $\mathrm{Fe}^{3+}(\mathrm{c})$.

static quenching, and the stoichiometric ratio of (+)PPBIPV and $\mathrm{Pd}^{2+}$ in methanol solution is 1:1. On the other hand, as for (-)-PPBIPV, $\mathrm{Sn}^{2+}$ can double the fluorescence of its aqueous solution, and the results shows that the stoichiometric relationship between $(-)$-PPBIPV and $\mathrm{Sn}^{2+}$ also is 1:1. Almost each ion can affect the fluorescence of (-)-PPBIPV in methanol solution, especially $\mathrm{Fe}^{3+}$, of which the fluorescence quenching efficiency is $97.5 \%$. The reason for this phenomenon may be attributed to the complexation of metal ions with (-)-PPBIPV and the electrostatic attraction between positive metal ions and negative charges in side-chain of the polymer. By analyzing and comparing their response to metal ions, the influence of side chain electrification on the sensing properties of conjugated polymers can be further discussed. All results show that these two conjugated polyelectrolytes could potentially be used as effective fluorescent sensors for detecting metal ions in biological and environmental media.
Acknowledgements: This work is financially supported by the "Shuangzhi" Project of Sichuan Agricultural University (No. 00770105) and the National University Student Innovation Program (No. 201910626096).

\section{References}

1. Duan C., Wang L., Zhang K., Guan X., Huang F., Conjugated zwitterionic polyelectrolytes and their neutral precursor as electron injection layer for high-performance polymer lightemitting diodes. Adv. Mater., 2011, 23, 1665-1669.

2. Seo J.H., Gutacker A., Sun Y., Wu H., Huang F., Cao Y., et al., Improved high-efficiency organic solar cells via incorporation of a conjugated polyelectrolyte interlayer. J. Am. Chem. Soc., 2011, $133,8416-8419$.

3. Liang J., Li K., Liu B., Visual sensing with conjugated polyelectrolytes. Chem. Sci., 2013, 4, 1377.

4. You J., Park T., Kim J., Heo J.S., Kim H.S., Kim H.O., et al., Highly fluorescent conjugated polyelectrolyte for protein sensing and cell-compatible chemosensing applications. ACS Appl. Mater. Inter., 2014, 6, 3305-3311. 
5. Wang Y., Liu B., Mikhailovsky A., Bazan G.C., Conjugated polyelectrolyte-metal nanoparticle platforms for optically amplified DNA detection. Adv. Mater., 2010, 22, 656-659.

6. Sun P., Lu X., Fan Q., Zhang Z., Song W., Li B., et al., WaterSoluble Iridium(III)-Containing Conjugated Polyelectrolytes with Weakened Energy Transfer Properties for Multicolor Protein Sensing Applications. Macromolecules, 2011, 44, 8763-8770.

7. Xia F., Zuo X., Yang R., Xiao Y., Kang D., Vallee-Belisle A., et al., Colorimetric detection of DNA, small molecules, proteins, and ions using unmodified gold nanoparticles and conjugated polyelectrolytes. Proc. Natl. Acad. Sci. USA, 2010, 107, 10837-10841.

8. Kim B., Jung I.H., Kang M., Shim H.K., Woo H.Y., Cationic conjugated polyelectrolytes-triggered conformational change of molecular beacon aptamer for highly sensitive and selective potassium ion detection. J. Am. Chem. Soc., 2012, 134, 3133-3138.

9. Roy S., Gunukula A., Ghosh B., Chakraborty C., A folic acid-sensitive polyfluorene based "turn-off" fluorescence nanoprobe for folate receptor overexpressed cancer cell imaging. Sensor. Actuat. B-Chem., 2019, 291, 337-344.

10. Vazquez-Guillo R., Martinez-Tome M.J., Kahveci Z., Torres I., Falco A., Mallavia R., et al., Synthesis and Characterization of a Novel Green Cationic Polyfluorene and Its Potential Use as a Fluorescent Membrane Probe. Polymers, 2018, 10, 938-957.

11. Hussain S., Malik A.H., Iyer P.K., Highly precise detection, discrimination, and removal of anionic surfactants over the full $\mathrm{pH}$ range via cationic conjugated polymer: an efficient strategy to facilitate illicit-drug analysis. ACS Appl. Mater. Inter., 2015, 7, 3189-3198.

12. Park S., Jeong J. E., Le V. S., Seo J., Yu B., Kim D.Y., et al., Enhanced Electron Transfer Mediated by Conjugated Polyelectrolyte and Its Application to Washing-Free DNA Detection. J. Am. Chem. Soc., 2018, 140, 2409-2412.

13. Bojanowski N.M., Bender M., Seehafer K., Bunz U.H.F., Discrimination of Saccharides by a Simple Array. Chemistry, 2017, 23, 12253-12258.

14. Park Y., Liu Z., Routh P.K., Kuo C.Y., Park Y.S., Tsai H., et al., DNA-assisted photoinduced charge transfer between a cationic poly(phenylene vinylene) and a cationic fullerene. Phys. Chem. Chem. Phys., 2015, 17, 15675-15678.

15. Jurin F.E., Buron C.C., Clément S., Mehdi A., Viau L., Lakard B., et al., Flexible and conductive multilayer films based on the assembly of PEDOT:PSS and water soluble polythiophenes. Org. Electron. , 2017, 46, 263-269.

16. Huber R.C., Ferreira A.S., Thompson R., Kilbride D., Knutson N.S., Devi L.S., et al., Long-lived photoinduced polaron formation in conjugated polyelectrolyte-fullerene assemblies. Science, 2015, 348, 1340-1343.

17. Molina P., Tarraga A., Oton F., Imidazole derivatives: a comprehensive survey of their recognition properties. Org. Biomol. Chem., 2012, 10, 1711-1724.

18. Ajani O.O., Aderohunmu D.V., Ikpo C.O., Adedapo A.E., Olanrewaju I.O., Functionalized Benzimidazole Scaffolds: Privileged Heterocycle for Drug Design in Therapeutic Medicine. Arch. Pharm. Chem. Life Sci., 2016, 349, 475-506.

19. Ermler S., Scholze M., Kortenkamp A., Seven benzimidazole pesticides combined at sub-threshold levels induce micronuclei in vitro. Mutagenesis, 2013, 28, 417-426.
20. Saluja P., Sharma H., Kaur N., Singh N., Jang D.O., Benzimidazolebased imine-linked chemosensor: chromogenic sensor for $\mathrm{Mg}^{2+}$ and fluorescent sensor for $\mathrm{Cr}^{3+}$. Tetrahedron, 2012, 68, 2289-2293.

21. Liu H., Zhang B., Tan C., Liu F., Cao J., Tan Y., et al., Simultaneous bioimaging recognition of $\mathrm{Al}^{3+}$ and $\mathrm{Cu}^{2+}$ in living-cell, and further detection of $\mathrm{F}^{-}$and $\mathrm{S}^{2}$ by a simple fluorogenic benzimidazolebased chemosensor. Talanta, 2016, 161, 309-319.

22. Kim Y.S., Lee J.J., Lee S.Y., Jo T.G., Kim C., A highly sensitive benzimidazole-based chemosensor for the colorimetric detection of $\mathrm{Fe}(\mathrm{ii})$ and $\mathrm{Fe}(\mathrm{iii})$ and the fluorometric detection of Zn(ii) in aqueous media. RSC Adv., 2016, 6, 61505-61515.

23. Velmurugan K., Mathankumar S., Santoshkumar S., Amudha S., Nandhakumar R., Specific fluorescent sensing of aluminium using naphthalene benzimidazole derivative in aqueous media. Spectrochim. Acta A, 2015, 139, 119-123.

24. Zhu H., Tong H., Gong Y., Shao S., Deng C., Yuan W.Z., et al., Fluorene- and benzimidazole-based blue light-emitting copolymers: Synthesis, photophysical properties, and PLED applications. J. Polym. Sci. A1, 2012, 50, 2172-2181.

25. Shim J.Y., Lee B.H., Song S., Kim H., Kim J.A., Kim I., et al., Synthesis and properties of the conjugated polymers with indenoindene and benzimidazole units for organic photovoltaics. J. Polym. Sci. A1, 2013, 51, 241-249.

26. Xiang G., Lin S., Cui W., Wang L., Zhou L., Li L., et al., Metal complex of polymer with 2-(pyridin-2-yl)-1H-benzo[d]imidazole unit as a selectivity-tunable chemosensor for amino acids. Sensor. Actuat. B-Chem., 2013, 188, 540-547.

27. Xiang G., Cui W., Lin S., Wang L., Meier H., Li L., et al., A conjugated polymer with ethyl 2-(2-(pyridin-2-yl)-1H-benzo[d] imidazol-1-yl) acetate units as a novel fluorescent chemosensor for silver(I) detection. Sensor. Actuat. B-Chem., 2013, 186, 741-749.

28. Kou C., He X., Jiang X., Ni Y., Liu L., Huangfu C., et al., Novel isoindigo-based conjugated polyelectrolytes: Synthesis and fluorescence quenching behavior with water-soluble poly(pphenylenevinylene)s. J. Polym. Sci. A1, 2015, 53, 2223-2237.

29. Gershon H., Clarke D.D., Gershon M., Preparation and Fungitoxieity of 3,6-Diehloroand 3,6-Dibromo-8-Quinolinols. Monatsh. Chem., 1994, 125, 723-730.

30. Wilson J.G., Hunt F.C., Iminodiacetic acid derivatives of benzimidazole. Synthesis of N-(Benzimidazol-2-ylmethyl) iminodiacetic acids. Aust. J. Chem., 1983, 36, 2317.

31. Cheng Y.-J., Luh T.-Y., Synthesizing optoelectronic heteroaromatic conjugated polymers by cross-coupling reactions. J. Organomet. Chem., 2004, 689, 4137-4148.

32. Willis-Fox N., Gutacker A., Browne M.P., Khan A.R., Lyons M.E.G., Scherf U., et al., Selective recognition of biologically important anions using a diblock polyfluorenepolythiophene conjugated polyelectrolyte. Polym. Chem.-UK, 2017, 8, 7151-7159.

33. Schanze K., Pinto M., Conjugated Polyelectrolytes: Synthesis and Applications. Synthesis, 2002, 2002, 1293-1309.

34. Tan C., Atas E., Muller J.G., Pinto M.R., Kleiman V.D., Schanze K.S., Amplified quenching of a conjugated polyelectrolyte by cyanine dyes. J. Am. Chem. Soc., 2004, 126, 13685-13694.

35. Shen H., Kou C., He M., Yang H., Liu K., Synthesis and surfactochromicity of 1,4-diketopyrrolo[3,4-c]pyrrole(DPP)-based 
anionic conjugated polyelectrolytes. J. Polym. Sci. A1, 2014, 52, 739-751.

36. Liu K., Li Y., Yang M., Synthesis and solution properties of a meta-linked anionic poly(phenylene ethynylene) conjugated polyelectrolyte. e-Polymers, 2012, 12, 1-8.

37. Tan C., Pinto M.R., Schanze K.S., Photophysics, aggregation and amplified quenching of a water-soluble poly(phenylene ethynylene). Chem. Commun., 2002, 446-447.

38. Crosby G.A., Demas J.N., Measurement of photoluminescence quantum yields. Review. J. Phys. Chem., 1971, 75, 991-1024.

39. Fan Q.-L., Zhang G.-W., Lu X.-M., Chen Y., Huang Y.-Q., Zhou Y., et al., Cationic phenyl-substituted poly(p-phenylenevinylene) related copolymers with efficient photoluminescence and synthetically tunable emissive colors. Polymer, 2005, 46, 11165-11173.

40. Treger J.S., Ma V.Y., Gao Y., Wang C.C., Wang H.L., Johal M.S., Tuning the optical properties of a water-soluble cationic poly(p-phenylenevinylene): surfactant complexation with a conjugated polyelectrolyte. J. Phys. Chem. B, 2008, 112, 760-763.

41. Long Y., Chen H., Wang H., Peng Z., Yang,Y., Zhang G., et al., Highly sensitive detection of nitroaromatic explosives using an electrospun nanofibrous sensor based on a novel fluorescent conjugated polymer. Anal. Chim. Acta, 2012, 744, 82-91.

42. Ceniceros-Gomez A.E., Ramos-Organillo A., Hernandez-Diaz J., Nieto-Martinez J., Contreras R., Castillo-Blum S.E., NMR study of the coordinating behavior of 2,6-bis(Benzimidazol-2'-yl) pyridine. Heteroatom Chem., 2000, 11, 392-398.

43. Zhang Y., Wang G., Zhang J., Study on a highly selective fluorescent chemosensor for $\mathrm{Fe}^{3+}$ based on 1,3,4-oxadiazole and phosphonic acid. Sensor. Actuat. B-Chem., 2014, 200, 259-268.

44. Dhara A., Jana A., Guchhait N., Ghosh P., Kar S.K., Rhodaminebased molecular clips for highly selective recognition of $\mathrm{Al}^{3+}$ ions: synthesis, crystal structure and spectroscopic properties. New J. Chem., 2014, 38, 1627-1634. 